\title{
Load capacity predictions of continuous concrete deep beams reinforced with GFRP bars
}

\author{
Othman Hameed Zinkaah*, Prof. Ashraf Ashour \\ School of Engineering, University of Bradford, UK
}

* Corresponding author.

E-mail address: othman.h.zinkaah@gmail.com (O. H. Zinkaah).

\begin{abstract}
Nine continuous concrete deep beams reinforced with glass fibre reinforced polymer (GFRP) bars were experimentally tested to failure. Three main parameters were investigated, namely, shear span-to-overall depth ratio, web reinforcement and size effect. The experimental results confirmed the impacts of web reinforcement and size effect that were not considered by the strut-and-tie method (STM) of the only code provision, the Canadian S806-12, that addressed such elements. The experimental results were employed to evaluate the applicability of the methods suggested by the American, European and Canadian codes as well as the previous studies to predict the load capacities of continuous deep beams reinforced with GFRP bars. It was found that these methods were unable to reflect the influences of size effect and/or web reinforcement, the impact of which has been confirmed by the current experimental investigation. Therefore, a new effectiveness factor was recommended to be used with the STM. Additionally, an upper-bound analysis was developed to predict the load capacity of the tested specimens considering a reduced bond strength of GFRP bars. A good agreement between the predicted results and the experimental ones was obtained with the mean and coefficient of variation values of 1.02 and $5.9 \%$, respectively, for the STM and 1.03 and $8.6 \%$, respectively, for the upper-bound analysis.
\end{abstract}

Keywords: plasticity theory; Continuous deep beams; polymer bars; effectiveness factor; strut-and-tie model; upper-bound analysis

\section{Introduction}

Fibre reinforced polymer (FRP) bars are used in structural members exposed to aggressive environmental conditions due to their superior characteristics over traditional steel reinforcement, such as corrosion resistance, high tensile capacity and high strength-toweight ratio that offers easier handling and installation. However, FRP reinforcement exhibits lack of ductility, low modulus of elasticity and low bond strength, affecting shear capacity and serviceability of structural FRP reinforced concrete members.

While the ACI 318-14 [1], Eurocode (EC2-2004) [2] and CSA A23.3 (2004) [3] have provided design guidelines for concrete deep beams reinforced with steel bars, only the CSA-S806-12 [4] proposed a guideline for the design of concrete deep beams reinforced with FRP using 
the same effectiveness factor formula recommended by CSA A23.3-04 for deep beams reinforced with steel rebars. These design guidelines were assessed against the experimental results of simply supported concrete deep beams reinforced with FRP bars [ $\underline{5-}$ $10]$ but have not yet been validated with the continuous ones reinforced with FRP bars.

Many experimental and computational investigations were conducted on simply supported deep beam specimens reinforced with FRP bars [5-13], while the continuous specimens, which are more practical and behave differently from the simply supported ones, have not yet been investigated experimentally or analytically. Due to the coexistence of high hogging moment and high shear within the interior shear spans of continuous beams, the statically indeterminate specimens behave differently from determinate ones. In contrast to the shallow beams, the strain response of deep beams is characterized by a nonlinear distribution, and hence the theory of elasticity is not applicable to deep beams [14], and instead the theory of plasticity is used for load capacity predictions.

The plasticity theory consists of the lower-bound, upper-bound, and uniqueness theorems $[15, \underline{16}$. In continuum mechanics to obtain an accurate solution, three main conditions must be achieved, namely equilibrium of stresses, compatibility of strains and constitutive relations [17]. Applying the lower-bound theorem needs to satisfy the yield criterion throughout the structural member and, then, equilibrium equations are used to estimate the load capacity [18]. The load calculated by the lower bound theorem is lower than or equal to the actual failure load. However, it is difficult to use the lower-bound analysis in some loading conditions and, instead, an upper-bound analysis can be applied, where a kinematically admissible failure mechanism is considered [18]. The load predicted by upper bound theorem is higher than or equal to the failure load. A unique solution can be obtained by achieving the highest lower-bound solution and the lowest upper-bound solution at the same time. The plasticity theorem assumes perfectly plastic behaviour of material in which no work hardening occurs after yielding. For ductile materials, useful results can be obtained using the plasticity theory, however for materials with limited ductility some modifications need to be applied [17]. Therefore, an effectiveness factor is introduced to absorb the shortcomings of applying the theory of plasticity to concrete structures.

This research aims to employ the upper and lower bound theorems to predict the load capacity of continuous concrete deep beams reinforced with GFRP bars. The applicability of STMs suggested by different codes and their modifications for deep beam specimens reinforced with steel or FRP bars, as well as the upper-bound analysis suggested for continuous specimens reinforced with steel rebars will be evaluated to assess their ability for load capacity predictions of continuous concrete deep beams reinforced with GFRP bars. Then, using the extracted experimental results, the existing upper and lower bound models 
are modified using new effectiveness factors able to account for the influences of web reinforcement and section size that the experimental results confirmed their impacts.

\section{Experimental program}

\subsection{Test specimens}

Nine continuous concrete deep beams reinforced with GFRP bars were designed and experimentally tested to failure. The effects of three main parameters were investigated in the experimental program, namely the shear span-to-overall depth ratio, $a / h$, web reinforcement and overall section depth, $h$. Beams with or without web reinforcement, having two shear span-to-overall depth ratios of 1.0 and 1.7 and three overall section depths of 300 $\mathrm{mm}, 600 \mathrm{~mm}$ and $800 \mathrm{~mm}$ were considered.

The experimental study consisted of six specimens having $a / h=1.0$ and three specimens having $a / h=1.7$. The specimens with $a / h=1.0$ can be divided into two groups one with shear reinforcement and the second one without shear reinforcement and each group had three overall section depths, $h$, of $300 \mathrm{~mm}, 600 \mathrm{~mm}$, and $800 \mathrm{~mm}$ as shown in Fig. 1 and Table 1 (G1-300-N, G1-600-N, G1-800-N, G1-300-W, G1-600-W and G1-800-W).

For specimens of $a / h=1.7$, three beams were designed, two of them having an overall depth of $300 \mathrm{~mm}$, one with shear reinforcement and the second one without shear reinforcement, while the third specimen was designed with an overall depth of $600 \mathrm{~mm}$ and with shear reinforcement as shown in Fig. 1 and Table 1 (G1.7-300-N, G1.7-300-W and G1.7-600-W). For specimens with web reinforcement, a web reinforcement ratio of $0.4 \%$ with $10 \mathrm{~mm}$ bar diameter of $200 \mathrm{~mm}$ centre to centre spacing was used for the horizontal and vertical web reinforcement to satisfy the recommendations of CSA-S806 [4]. All specimens had the same beam width and development length of $175 \mathrm{~mm}$ and $400 \mathrm{~mm}$, respectively. Both top and bottom longitudinal reinforcement ratios, $A_{f} / b h$, were kept constant at $1.2 \%$ for all test beams, achieved by providing $2 \varnothing 16+1 \varnothing 20 \mathrm{~mm}$ for $300 \mathrm{~mm}$ deep beams, $4 \varnothing 16+2 \varnothing 20 \mathrm{~mm}$ for $600 \mathrm{~mm}$ deep beams and $6 \emptyset 20 \mathrm{~mm}$ for $800 \mathrm{~mm}$ deep beams as shown in Fig. 1, where $A_{f}$ is the area of longitudinal reinforcement. Table 2 shows the actual mechanical properties of the used GFRP bars that were tested in the laboratory according to the ACI 440.3R [19]. The clear cover to the face of the vertical stirrups was $20 \mathrm{~mm}$, while concrete cover to the centre of the top and bottom longitudinal reinforcements was scaled with the overall section depth, $h$, by a ratio of 0.133 . By doing so, the $a / d$ ratio was constant for all specimens that had the same $a / h$ ratio, as shown in Table 1 . The dimension of the bearing plates in the direction of the span length was scaled with the section depth, $h$, to be $0.25 h$ for the end supports plates and $0.35 \mathrm{~h}$ for the loading and intermediate support plates in order to eliminate the effect of bearing plates as a variable, as shown in Table 1. The width and thickness of all bearing plates were kept constant at $200 \mathrm{~mm}$ and $40 \mathrm{~mm}$, respectively. 
The beam notation was defined according to the reinforcement type, $a / h$ ratio, overall section depth and presence of web reinforcement. The first part, G, refers to GFRP, while the second and third parts indicate the $a / h$ ratio $(1.0$ or 1.7$)$ and the overall section depth $(300 \mathrm{~mm}, 600 \mathrm{~mm}$ and $800 \mathrm{~mm}$ ), respectively. The fourth part stands for the web reinforcement: $W$ for beams with orthogonal web reinforcement of $0.4 \%$ in each direction, and $\mathrm{N}$ for beams with no web reinforcement. The compressive strength was designed to be constant for all of the specimens with a concrete strength, but due to unavoidable circumstances, the strength of concrete varied slightly as shown in Table 3. A $2500 \mathrm{kN}$ hydraulic actuator was used to apply a symmetrical two-point loading system, one point load at the middle of each span, using a spreader steel beam as shown in Fig. 2.

Test results of failure modes and loads of the beams tested are presented below. However, other experimental results including beam deflections, FRP reinforcement strains and crack width are presented in a companion paper [20] as the main focus of this paper is to evaluate the applicability of the strut and tie models suggested by various codes as well as the previous studies to predict the load capacity of continuous deep beams reinforced with FRP bars.

\subsection{Failure modes and loads}

A typical shear failure occurred in all deep beam specimens represented by a diagonal crack extending between the loading point and the intermediate support as shown in Figs. 3 and A.1. Accordingly, each beam separated into two parts: one rotated about the exterior support, while the other part rested over the other two supports.

Table 3 presents the total failure load, $P_{t}$, external shear strength (end support reaction at failure), $\mathrm{V}_{\mathrm{E}}$, and internal shear strength of one span, $V_{I}$. The results showed that the web reinforcement improved the total load capacities by about $10 \%$ and $18 \%$ for specimens having $a / h=1.0$ and $a / h=1.7$, respectively as shown in Table 3. The increase in $a / h$ ratio from 1.0 to 1.7 , led to reductions in the load carrying capacities by about $33 \%$ and $37 \%$ for specimens of $300 \mathrm{~mm}$ height with and without web reinforcement, respectively, and $29 \%$ for specimens of $600 \mathrm{~mm}$ height with web reinforcement, taking into consideration the small difference of concrete compressive strength.

An expression of normalised total failure load, $P_{t} / f_{c}^{\prime} b h$, was used to investigate the size effect, where $P_{t}$ is the total failure load. In beams with and without web reinforcement and having $a / h$ ratios of 1.0 and 1.7 , the results showed a significant size effect when the section depth increased from $300 \mathrm{~mm}$ to $600 \mathrm{~mm}$. Increasing the section depth from $300 \mathrm{~mm}$ to 600 $\mathrm{mm}$ resulted in a reduction of the normalised total load by about $26 \%$ for beams with and without web reinforcement and having $a / h=1.0$, and about $22 \%$ reduction in beams with 
web reinforcement and having $a / h=1.7$. That reduction of the normalised total load was slightly higher in beams with $a / h=1.0$ than those with $a / h=1.7$.

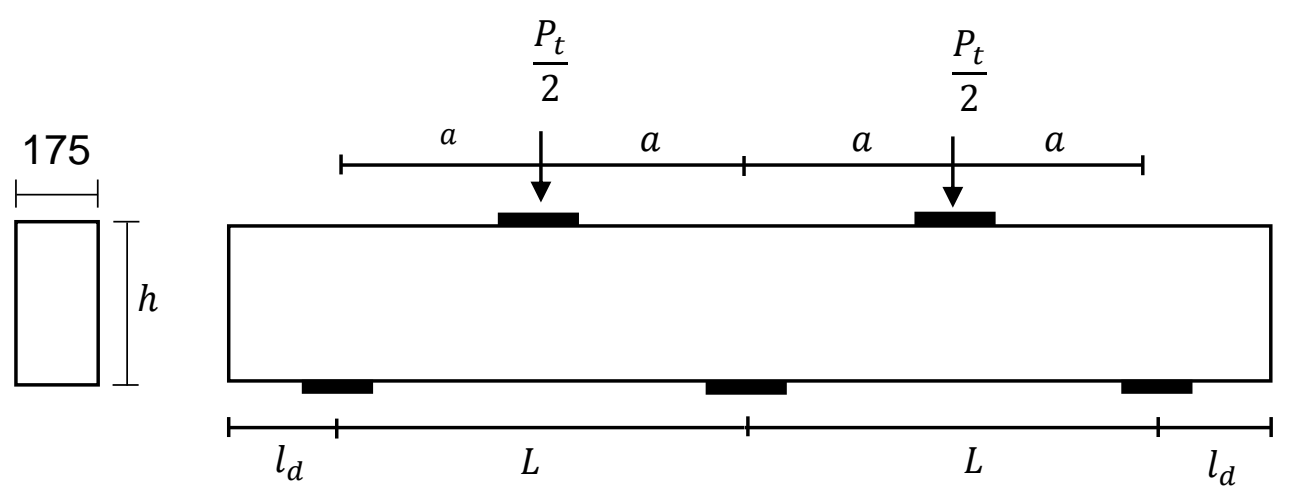

G1-300-N

G1.7-300-N

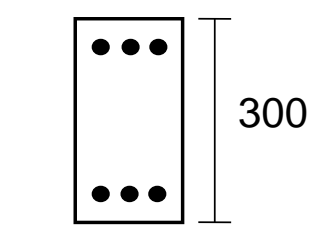

$2 \emptyset 16+1 \varnothing 20$

top and bottom

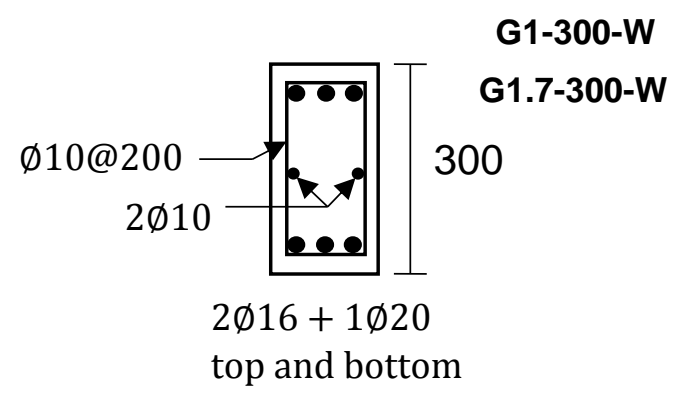

G1-600-N

G1-600-W

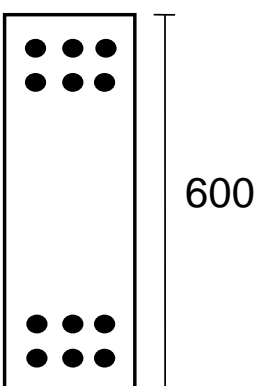

$4 \emptyset 16+2 \varnothing 20$

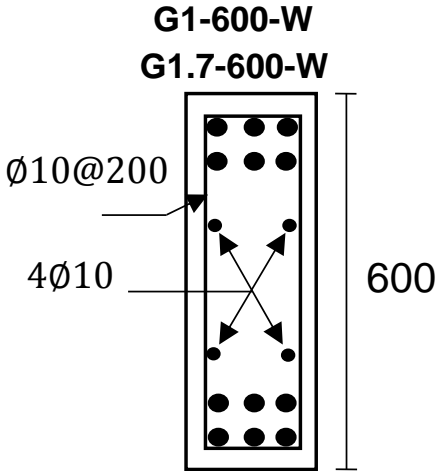

top and bottom

$4 \emptyset 16+2 \emptyset 20$

top and bottom

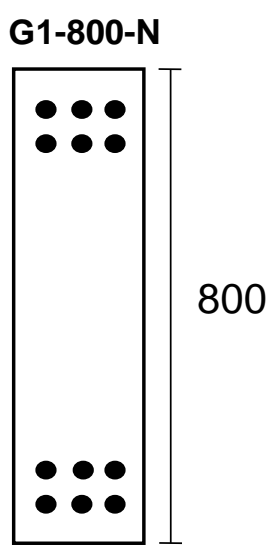

$6 \emptyset 20$

top and bottom

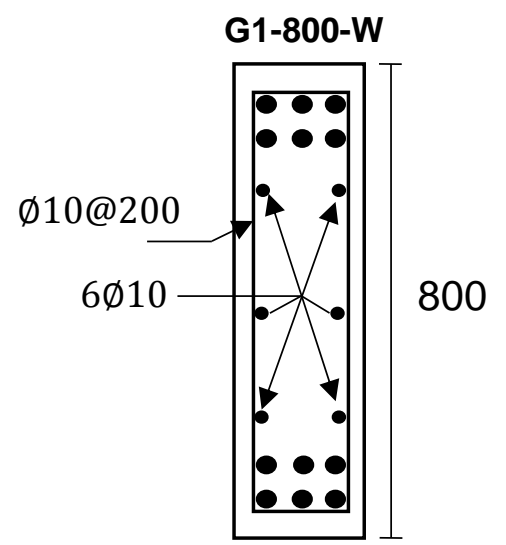

$6 \varnothing 20$

top and bottom 
Fig. 1: Details of test specimens (all dimensions are in $\mathrm{mm}$ )

Table 1: Geometrical dimensions of test specimens

\begin{tabular}{|c|c|c|c|c|c|c|c|c|c|c|}
\hline \multirow[b]{2}{*}{ Specimen } & \multirow[b]{2}{*}{$\begin{array}{c}h \\
\mathrm{~mm}\end{array}$} & \multirow[b]{2}{*}{$\begin{array}{c}d \\
\mathrm{~mm}\end{array}$} & \multirow[b]{2}{*}{$\begin{array}{c}a \\
\mathrm{~mm}\end{array}$} & \multirow[b]{2}{*}{$a / h$} & \multirow[b]{2}{*}{$a / d$} & \multirow[b]{2}{*}{$\begin{array}{c}L \\
\mathrm{~mm}\end{array}$} & \multirow[b]{2}{*}{$\begin{array}{c}l_{d} \\
\mathrm{~mm}\end{array}$} & \multirow[b]{2}{*}{$\begin{array}{c}b \\
\mathrm{~mm}\end{array}$} & \multicolumn{2}{|c|}{ Bearing plate } \\
\hline & & & & & & & & & $\begin{array}{l}\text { Load and } \\
\text { mid- } \\
\text { support } \\
\text { plates mm }\end{array}$ & $\begin{array}{l}\text { End } \\
\text { plates } \\
\mathrm{mm}\end{array}$ \\
\hline G1-300-N & \multirow{2}{*}{300} & \multirow{2}{*}{260} & \multirow{2}{*}{300} & \multirow{6}{*}{1.0} & \multirow{6}{*}{1.15} & \multirow{2}{*}{600} & \multirow{9}{*}{400} & \multirow{9}{*}{175} & 105 & 75 \\
\hline G1-300-W & & & & & & & & & 105 & 75 \\
\hline G1-600-N & \multirow{2}{*}{600} & \multirow{2}{*}{520} & \multirow{2}{*}{600} & & & \multirow{2}{*}{1200} & & & 210 & 150 \\
\hline G1-600-W & & & & & & & & & 210 & 150 \\
\hline G1-800-N & \multirow{2}{*}{800} & \multirow{2}{*}{695} & \multirow{2}{*}{800} & & & \multirow{2}{*}{1600} & & & 280 & 200 \\
\hline G1-800-W & & & & & & & & & 280 & 200 \\
\hline G1.7-300-N & \multirow{2}{*}{300} & \multirow{2}{*}{260} & \multirow{2}{*}{510} & \multirow{3}{*}{1.7} & \multirow{3}{*}{1.96} & \multirow{2}{*}{1020} & & & 105 & 75 \\
\hline G1.7-300-W & & & & & & & & & 105 & 75 \\
\hline G1.7-600-W & 600 & 520 & 1020 & & & 2040 & & & 210 & 150 \\
\hline
\end{tabular}

Table 2: Mechanical properties of GFRP bars

\begin{tabular}{|c|c|c|c|c|c|}
\hline $\begin{array}{c}\text { Bar diameter } \\
(\mathrm{mm})\end{array}$ & $\begin{array}{c}\text { Area } \\
\left(\mathrm{mm}^{2}\right)\end{array}$ & $\begin{array}{c}\text { Modulus of } \\
\text { elasticity } \\
(\mathrm{MPa})\end{array}$ & $\begin{array}{c}\text { Tensile strength } \\
(\mathrm{MPa})\end{array}$ & $\begin{array}{c}\text { Rupture } \\
\text { strain }\end{array}$ & $\begin{array}{c}\text { Bond strength } \\
(\mathrm{MPa})\end{array}$ \\
\hline 10 & 73 & 62600 & 1100 & 0.0194 & 18.6 \\
\hline 16 & 180 & 48700 & 920 & 0.0199 & 28.2 \\
\hline 20 & 278 & 43500 & 760 & 0.0188 & 21.6 \\
\hline
\end{tabular}




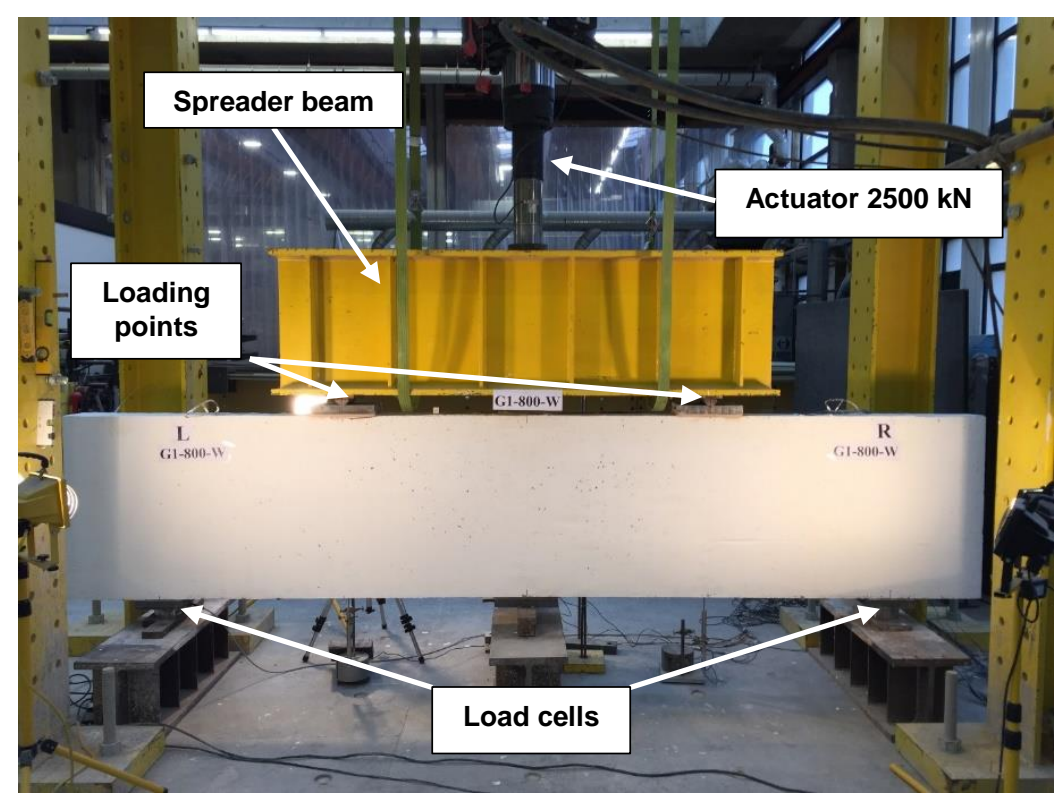

Fig. 2: Test setup

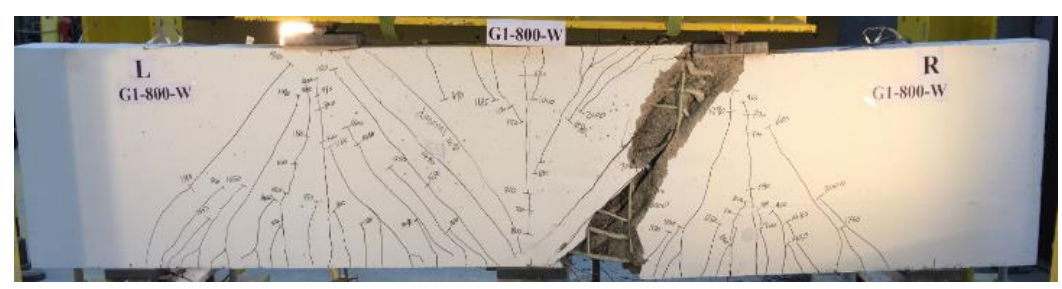

Fig. 3: Cracking propagation and failure modes of specimen G1-800-W

Table 3: Failure loads and support reactions

\begin{tabular}{|c|c|c|c|c|}
\hline Beam & $f_{c}^{\prime}(\mathrm{MPa})$ & $P_{t}(\mathrm{kN})$ & $V_{E}(\mathrm{kN})$ & $V_{I}(\mathrm{kN})$ \\
\hline G1-300-N & 56.6 & 937.3 & 145.76 & 322.9 \\
\hline G1-300-W & 55.3 & 1005.8 & 166.95 & 335.9 \\
\hline G1-600-N & 56.6 & 1388.0 & 214.73 & 479.3 \\
\hline G1-600-W & 53.6 & 1439.4 & 217.84 & 501.8 \\
\hline G1-800-N & 56.6 & 1957.1 & 304.25 & 674.3 \\
\hline G1-800-W & 53.6 & 2050.3 & 305.33 & 719.8 \\
\hline G1.7-300-N & 52.5 & 547.8 & 78.17 & 195.7 \\
\hline G1.7-300-W & 52.1 & 639.7 & 105.68 & 214.2 \\
\hline G1.7-600-W & 52.1 & 1000.5 & 146.85 & 353.4 \\
\hline
\end{tabular}

\section{Strut-and-tie model for continuous FRP reinforced concrete deep beams}

Strut-and-tie models (STM) were recommended by many codes of practice for discontinuity regions where elasticity theory cannot be applied [1-4]. STM is based on the lower bound theorem of the plasticity theory and requires satisfaction of equilibrium and yield conditions [14]. The proposed STM analyses discontinuity region members as a truss model [21] in 
which, compression and tension stresses are transferred by concrete struts and reinforcement ties, respectively as shown in Fig. 4(a). Axial forces of struts and ties are interconnected at the nodes as shown in Fig. 4(b) and Fig. 4(c). Struts, ties, and nodes must be properly proportioned to resist the applied forces. Using basic truss theory and knowing the applied load, the forces in concrete struts and ties can be calculated. Owing to the failure of concrete strut, the external $\left(V_{E}\right)$ and internal $\left(V_{I}\right)$ shear strengths of continuous deep beams can be calculated as follows:

$$
\begin{aligned}
& F_{E}=v f_{c}^{\prime} b W_{E S} \\
& V_{E}=F_{E} \sin \theta \\
& F_{I}=v f_{c}^{\prime} b W_{I S} \\
& V_{I}=F_{I} \sin \theta \\
& \theta=\tan ^{-1} \frac{\left(h-c-c^{\prime}\right)}{a}
\end{aligned}
$$

A strength reduction factor of 0.85 was recommended by the $\mathrm{ACl}$ code [1] to reflect the effective concrete strength under a sustained compression. Accordingly, to calculate the load capacity according to the $\mathrm{ACl}$ code, Eqs 1 and 3 are multiplied by 0.85 .

where $F_{E}$ and $F_{I}$ are the load capacities of exterior and interior concrete struts, $v$ is the concrete effectiveness factor, $b$ is the beam width, $W_{E S}$ and $W_{I S}$ are the average widths of the exterior and the interior compression struts, respectively, $\theta$ is the slope of the concrete strut, $c$ ' and $c$ are concrete covers of top and bottom longitudinal reinforcements, respectively, $h$ is the overall section depth, and $a$ is the shear span. An average of top and bottom strut widths was taken to determine the failure load as follows:

$$
\begin{aligned}
& W_{E S}=\frac{\left(W_{E S}\right)_{t}+\left(W_{E S}\right)_{b}}{2} \\
& W_{I S}=\frac{\left(W_{I S}\right)_{t}+\left(W_{I S}\right)_{b}}{2}
\end{aligned}
$$

where $\left(W_{E S}\right)_{t}$ and $\left(W_{E S}\right)_{b}$ are the top and bottom widths of the exterior strut, respectively, $\left(W_{I S}\right)_{t}$ and $\left(W_{I S}\right)_{b}$ are the top and bottom widths of the interior strut, respectively. To take into account the presence of two struts in the loading zone, namely external and internal struts, the width of the loading plate was subdivided into two parts. The width of each part was taken equivalent to the load ratio transfers to the connected strut, in which $\eta l_{L P}$ is for the exterior strut and $(1-\eta) l_{L P}$ is for the interior strut, where $\eta$ is the ratio of the end reaction to the applied load, $l_{L P}$ is the width of the loading plate, as shown in Fig. 4 [22-24]. The effective width of the diagonal concrete strut depends on the width of the bearing plate, width of the tie and angle formed between the strut and tie as presented in the equations below. 


$$
\begin{gathered}
\left(W_{E S}\right)_{t}=\eta l_{L P} \sin \theta+W_{t n} \cos \theta \\
\left(W_{E S}\right)_{b}=l_{E P} \sin \theta+W_{b n} \cos \theta \\
\left(W_{I S}\right)_{t}=(1-\eta) l_{L P} \sin \theta+W_{t n} \cos \theta \\
\left(W_{I S}\right)_{b}=0.5 l_{I P} \sin \theta+W_{b n} \cos \theta
\end{gathered}
$$

where $l_{E P}$ is the width of the exterior support bearing plate, $l_{I P}$ is the width of the interior support bearing plate, $W_{t n}$ is the effective depth of the top tie which is equal to $2 c^{\prime}, W_{b n}$ is the effective depth of the bottom tie which is equal to $2 c$. The experimental and 2-D finite element analysis results of the tested specimens showed that the loads transferred to the end and intermediate support of each span at failure of the two-span continuous concrete deep beams reinforced with GFRP bars were about $15 \%$ and $35 \%$ of the total applied load, respectively, therefore, in this study the value of $\eta$ was taken to be 0.3 . Based on the above, the total load $P_{t}$ was calculated as follows:

$$
P_{t}=\min \left\{\begin{array}{l}
\frac{V_{E}}{0.15} \\
\frac{V_{I}}{0.35}
\end{array}\right.
$$

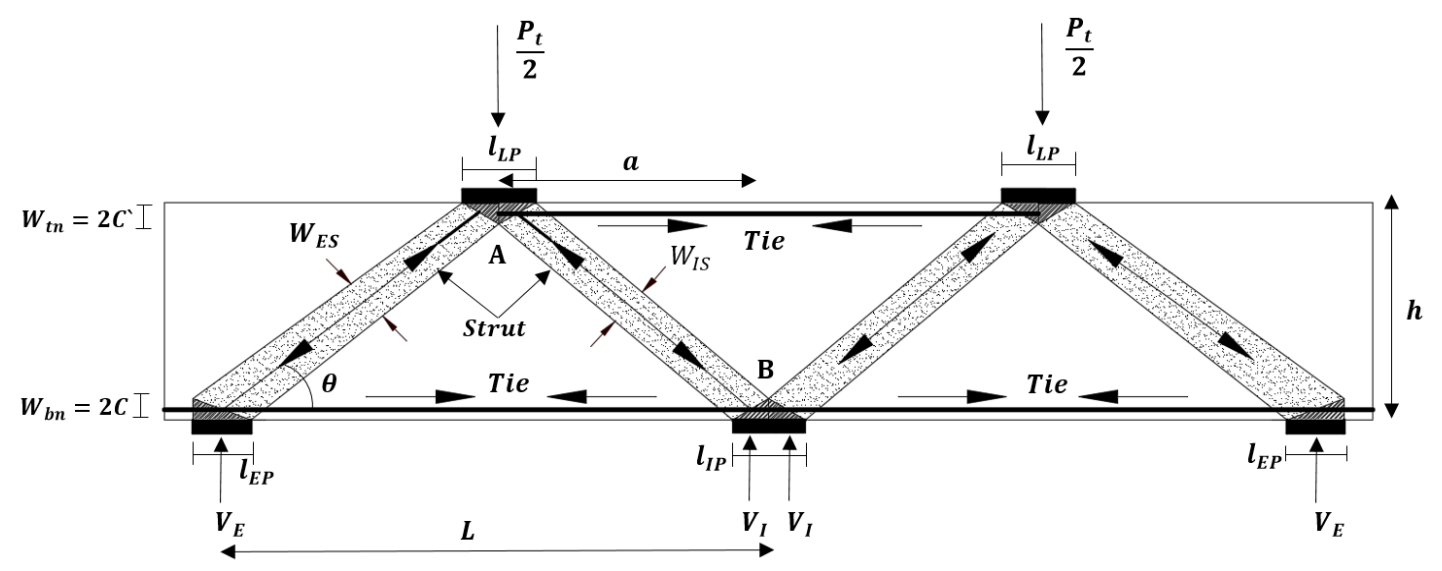

(a) 


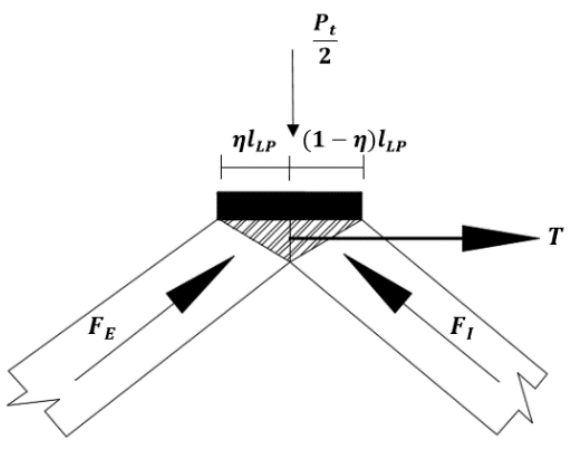

(b)

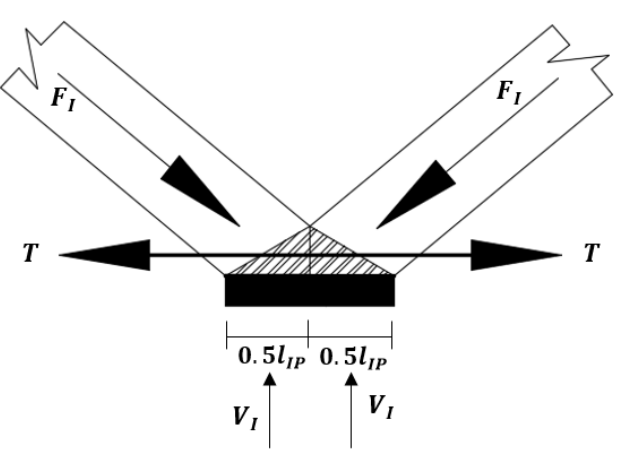

(c)

Fig. 4: (a) Schematic STM for continuous deep beams, (b) joint A that shows loading point, (c) joint B that shows intermediate support

\subsection{Comparisons of the measured load capacities with the predictions of the code provisions}

The applicability of the STMs of the American (ACI 318-14) [1], European (EC2-1992) [2] and Canadian code (S806-2012) [4] for predicting the shear strength of concrete deep beams reinforced with GFRP bars are evaluated in this section using the simplified STM presented above. To apply the STM of the three code provisions, only the effectiveness factor of concrete was changed and taken according to Table 4.

It can be noticed that the effectiveness factor of the American code depends on the presence of orthogonal web reinforcement (in case of the bottle-shaped strut) and does not consider the effect of concrete compressive strength and longitudinal reinforcement ratio. However, the effectiveness factor of the European code considers the concrete compressive strength and neglects the effect of web reinforcement and longitudinal reinforcement ratio. The effectiveness factor of the Canadian code takes into account the effect of the tensile strain of the longitudinal reinforcement and, hence, the effect of longitudinal reinforcement ratio, while influences of compressive strength and web reinforcement are neglected. According to the STMs of the Canadian and European codes, minimum web reinforcement is recommended for the crack control, but these two provisions do not consider the effect of web reinforcement on the shear strength of deep beams. While, according to the STM of the American code, providing the minimum web reinforcement results in an increase of the shear strength of the diagonal strut by $25 \%$ in case of the bottle-shaped strut.

Fig. 5 and Table 5 show the relationship between the experimental results and the calculated total load capacities using the STM of the American, European and Canadian codes. The experimental-to-calculated shear capacities (for one span) of the internal supports $\left(V_{I}\right)$ are included in Table 5. The results show that the STM of the ACI 318-14 overestimated the load capacities of the test specimens with a mean and a coefficient of 
variation for the experimental-to-calculated load capacities of 0.88 and $15.6 \%$, respectively. The overestimation of the STM of the American code was confirmed by some of the previous researchers [7-9] for simply supported deep beams reinforced with the FRP rebars. This could be attributed for two main reasons. The first one is the non-consideration of the size effect as confirmed by the predictions of specimens having an overall section depth of more than $300 \mathrm{~mm}$. The second reason may be related to the exaggeration of the web reinforcement effect on the shear strength, especially for specimens having low $a / h$ ratio.

To calculate the concrete effectiveness factor of the Canadian code, strain in the longitudinal reinforcement, $\varepsilon_{f}$, was assumed. To make sure that the calculated load achieved the assumed strain, an iterative process was implemented. The iterative process was repeated until the calculated load in the last iteration achieved a strain level similar to the assumed strain as shown in Fig. 6, where $E_{f}$ and $A_{f}$ are the modulus of elasticity and the area of longitudinal reinforcement, respectively. Conservative predictions of the total load capacities of the test specimens were shown by the CSA S806-12 with a mean for the ratio between the experimental and calculated results of 2.63 and a coefficient of variation of $34 \%$ as shown in Fig. 5 and Table 5. The conservative predictions of CSA S806-12 were also shown by previous investigations for simply supported deep beams reinforced with the FRP rebars $[\underline{9}, 25]$. The shear strength according to the STM of Canadian code was conservative because there is an inverse relationship between the strain and effectiveness factor of the Canadian code. The high strain in GFRP bars leads to an increase in the principal tensile strain $\left(\varepsilon_{1}\right)$ which, in return, reduces the effectiveness factor of concrete, leading to a conservative shear strength prediction for the specimens reinforced with GFRP bars. It is worth mentioning that the STM of the Canadian code (S806-2012) recommended the same concrete effectiveness factor that was suggested by the STM of CSA A23.3-04 for deep beams reinforced with steel rebars. In deep beams reinforced with steel bars, the strain of longitudinal reinforcement is less than that of FRP bars, and therefore it is believed that the STM of the Canadian code provides more reasonable predictions for the shear strength of deep beams reinforced with steel rebars.

Unlike the STMs of the American and the Canadian codes, the closest predictions to the test results were obtained by the STM of the European code with a mean for the experimental-tocalculated load capacity values of 1.08 and a coefficient of variation of $14.8 \%$. However, the predictions of the European code were slightly conservative. Similar to the STM of the Canadian code, the European code does not consider the influence of the section depth and web reinforcement in the prediction of the shear strength as shown in Fig. 7 that presents the relationship between the normalised total load carrying capacity $\left(P_{t} / b h f_{c}^{\prime}\right)$ and the overall section depth $(h)$. 
Therefore, it can be concluded that the effectiveness factors of the STMs of the American, European and Canadian codes did not reflect adequately the effect of main parameters governing the behaviour of GFRP-reinforced concrete continuous deep beams and, consequently, the effectiveness factor of the STM model may need to be modified.

Table 4: Strut effectiveness factors according to ACI 318-14, EN 1992-1-1 and CSA-S80612 codes

\begin{tabular}{|c|l|c|}
\hline Code & \multicolumn{1}{|c|}{ Strut effectiveness factor $(v)$} \\
\hline \multirow{2}{*}{ ACI 318-14 [1] } & $\begin{array}{l}\text { Bottle-shaped struts with reinforcement satisfying the } \\
\text { ACl 318-14 }\end{array}$ & 0.75 \\
\cline { 2 - 3 } & $\begin{array}{l}\text { Bottle-shaped struts without reinforcement satisfying the } \\
\text { ACl 318-14 }\end{array}$ & 0.6 \\
\hline EN 1992-1-1 [2] & \multicolumn{1}{|c|}{$0.6\left(1-\frac{f_{c}^{\prime}}{250}\right)$} \\
\hline CSA-S806-12 [4] & $\frac{1}{0.8+170 \varepsilon_{1}} \leq 0.85, \varepsilon_{1}=\left[\varepsilon_{f}+\left(\varepsilon_{f}+0.002\right) \cot ^{2} \theta_{s}\right]$ \\
\hline$\varepsilon_{1}$ is the principal tensile strain and $\varepsilon_{f}$ is the tensile strain in FRP bars. \\
\hline
\end{tabular}

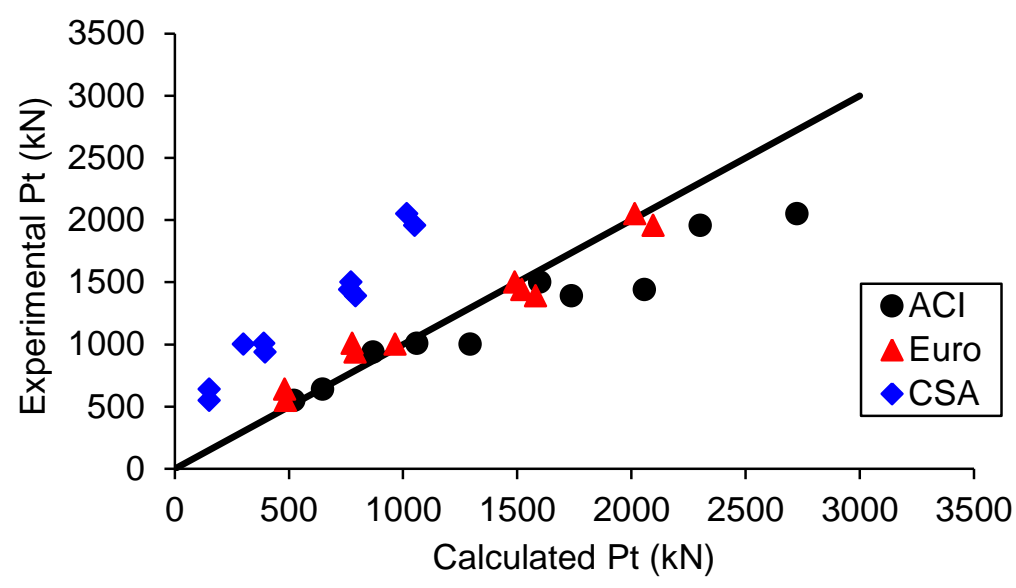

Fig. 5: Comparisons between experimental results and predictions of the STM of the American, European and Canadian codes

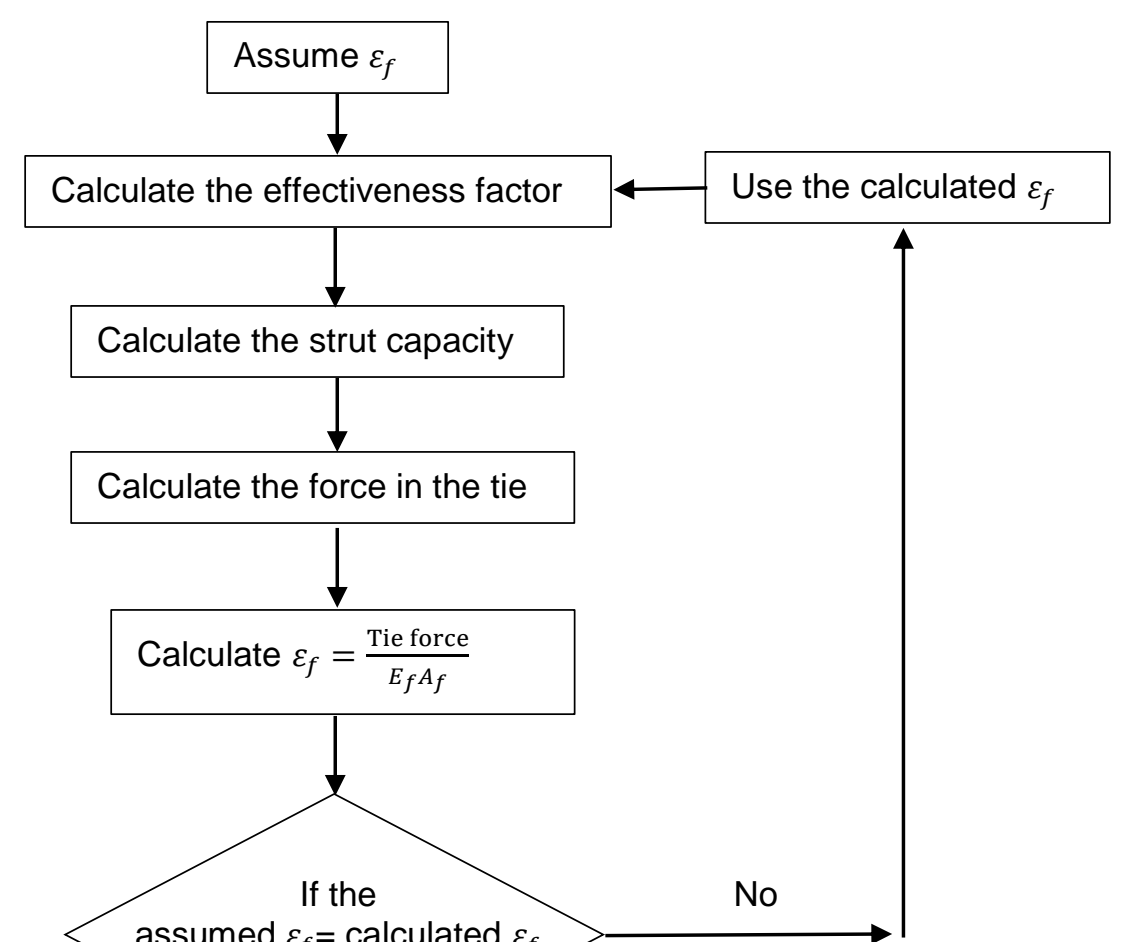


Fig. 6: Iteration process to calculate the effectiveness factor of the Canadian code

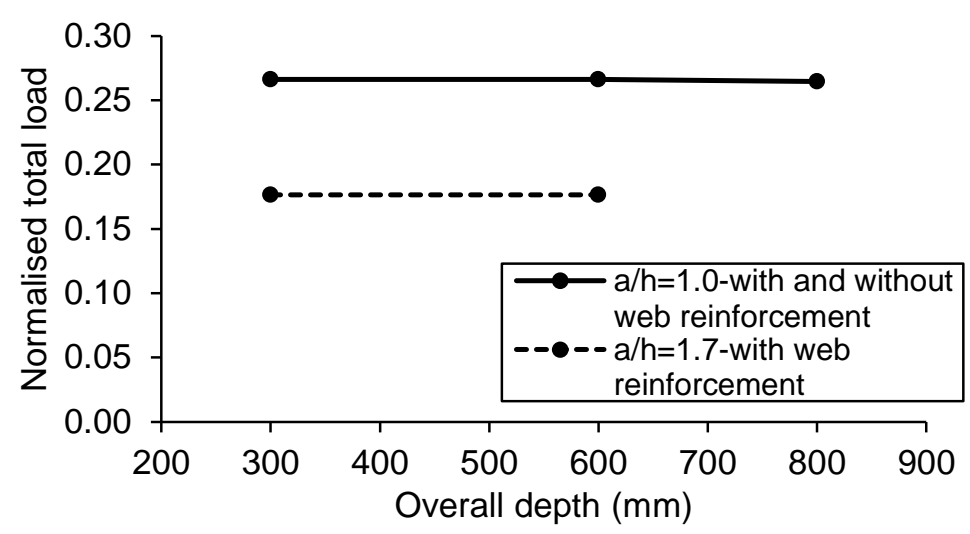

Fig. 7: Web reinforcement and size effect for the test specimens according to the STM of the European code

Table 5: Comparisons between experimental results and those predicted using the codes and the proposed effectiveness factors

\begin{tabular}{|c|c|c|c|c|c|c|c|c|c|c|}
\hline \multirow{2}{*}{ Specimens } & \multicolumn{5}{|c|}{ Total Load $\left(P_{t}\right)$} & \multicolumn{4}{|c|}{ Internal shear force $\left(V_{I}\right)$} \\
\cline { 2 - 12 } & $\begin{array}{c}\text { Exp. } \\
\text { kN }\end{array}$ & $\frac{\text { Exp }}{\text { ACI }}$ & $\frac{\text { Exp }}{\text { Euro }}$ & $\frac{\text { Exp }}{\text { CSA }}$ & $\frac{\text { Exp }}{\text { Proposed }}$ & $\begin{array}{c}\text { Exp. } \\
\text { kN }\end{array}$ & $\frac{\text { Exp }}{\text { ACI }}$ & $\frac{\text { Exp }}{\text { Euro }}$ & $\frac{\text { Exp }}{\text { CSA }}$ & $\frac{\text { Exp }}{\text { Proposed }}$ \\
\hline G1-300-N & 937.3 & 1.08 & 1.19 & 2.37 & 1.06 & 322.9 & 1.06 & 1.17 & 2.33 & 1.04 \\
\hline G1-300-W & 1005.8 & 0.95 & 1.29 & 2.58 & 1.05 & 335.9 & 0.90 & 1.23 & 2.46 & 1.00 \\
\hline G1-600-N & 1388.0 & 0.80 & 0.88 & 1.75 & 0.95 & 479.3 & 0.79 & 0.87 & 1.73 & 0.94 \\
\hline G1-600-W & 1439.4 & 0.70 & 0.95 & 1.88 & 0.93 & 501.8 & 0.70 & 0.94 & 1.87 & 0.93 \\
\hline G1-800-N & 1957.1 & 0.85 & 0.93 & 1.86 & 1.10 & 674.3 & 0.84 & 0.92 & 1.83 & 1.08 \\
\hline G1-800-W & 2050.3 & 0.75 & 1.02 & 2.02 & 1.09 & 719.8 & 0.75 & 1.02 & 2.02 & 1.09 \\
\hline G1.7-300-N & 547.8 & 1.05 & 1.13 & 3.63 & 1.01 & 195.7 & 1.07 & 1.15 & 3.70 & 1.03 \\
\hline G1.7-300-W & 639.7 & 0.99 & 1.33 & 4.26 & 1.01 & 214.2 & 0.95 & 1.27 & 4.07 & 0.97 \\
\hline G1.7-600-W & 1000.5 & 0.77 & 1.04 & 3.33 & 0.96 & 353.4 & 0.78 & 1.05 & 3.36 & 0.97 \\
\hline & Mean & 0.88 & 1.08 & 2.63 & 1.02 & Mean & 0.87 & 1.07 & 2.60 & 1.01 \\
\cline { 2 - 11 } & SD\% & 13.4 & 16.0 & 90.2 & 6.0 & SD\% & 13.4 & 14.4 & 88.5 & 5.87 \\
\cline { 2 - 10 } & CV\% & 15.6 & 14.8 & 34.3 & 5.9 & CV\% & 15.4 & 13.5 & 34.1 & 5.8 \\
\hline
\end{tabular}




\subsection{Effectiveness factors collected from the literature}

The effectiveness factor, $v$, is applied to account for the brittle behaviour of concrete and to overcome the inaccurate assumption that concrete is a rigid perfectly plastic material $[16, \underline{16}$, $\underline{26}$, 27]. A number of effectiveness factors were collected from the literature to evaluate whether they can be used to predict the load capacity of the continuous concrete deep beams reinforced with GFRP bars instead of those proposed by the code provisions, as shown in Table 6. Some of those factors were taken as a constant value, such as those recommended by Rogowsky and MacGregor [28] and Marti [29]. While other factors were proposed as a function of the parameters that govern the behaviour of the concrete structure, such as those suggested by Nielsen [16] and Bergmeister et al. [30], that considered the effect of concrete compressive strength only. Collins and Mitchell [31] proposed an effectiveness factor considering an explicit effect of the principal tensile and compressive strains of concrete and implicit effects of the longitudinal reinforcement and shear span-to-depth ratio. STM of CSA A23.3-04 [3] and CSA-S806-12 [4] have adopted Collins and Mitchell's factor for steel and FRP bars, respectively. Foster and Gillbert [32] modified the effectiveness factor proposed by Collins and Mitchell's [31] to account for the effect of compressive strength on the principal compressive strain. This effect of concrete compressive strength was presented linearly by taking strain equal to 0.002 at peak stress of concrete with a compressive strength of $20 \mathrm{MPa}$ and strain equal to 0.003 at the peak stress of concrete with a compressive strength of $100 \mathrm{MPa}$. Tan and Cheng [33] proposed an effectiveness factor considering both effects of section size and web reinforcement. The effectiveness factors proposed by Chen [34] and Warwick and Foster [26] are also considered as listed in Table 6.

The collected effectiveness factors were used with the STM presented earlier, namely Eqs 1 to 12 , to estimate the total load capacities of the test specimens of the current study.

Table 7 shows the values of mean, standard deviation and coefficient of variation for the ratio of experimental-to-calculated total load capacity of the tested specimens using the collected effectiveness factor presented in Table 6. The results showed that Warwick and Foster's effectiveness factor [26] gives better predictions compared with those proposed by other researchers with a mean and a coefficient of variation values for the experimental-tocalculated results of 1.02 and $24.1 \%$, respectively. Fig. 8 shows the relationship between the experimental and predicted results using Warwick and Foster's effectiveness factor. However, the omission of section depth and web reinforcement makes of Warwick and 
Foster's effectiveness factor unsuitable to be recommended for load predictions of the current study.

Table 6: Collected effectiveness factors of concrete

\begin{tabular}{|c|c|c|}
\hline & Reference & Proposed effectiveness factor \\
\hline 1 & Rogowsky and MacGregor [28] & $v=0.85$ \\
\hline 2 & Marti [29] & $v=0.6$ \\
\hline 3 & Nielsen [16] & $v=0.8-\frac{f_{c}^{\prime}}{200}\left(f_{c}^{\prime}\right.$ in $\left.\mathrm{MPa}\right)$ \\
\hline 4 & Bergmeister et al. [30] & $v=\left(0.5+\frac{1.25}{\sqrt{f_{c}^{\prime}}}\right) \quad$ for $20<f_{c}^{\prime}<80 \mathrm{MPa}$ \\
\hline 5 & Collins and Mitchell [31] & $\begin{array}{c}v=\frac{1}{0.8+170 \varepsilon_{1}} \leq 0.85 \\
\varepsilon_{1}=\left[\varepsilon_{s}+\left(\varepsilon_{s}+0.002\right) \cot ^{2} \theta_{s}\right]\end{array}$ \\
\hline 6 & Foster and Gilbert [32] & $v=\frac{1}{1.14+\left(0.64+\frac{f_{c}^{\prime}}{470}\right)\left(\frac{a}{d}\right)^{2}}$ \\
\hline 7 & Tan and Cheng [33] & $\begin{array}{c}\xi=\xi .8+\frac{0.4}{\sqrt{1+(l-s) / 50}} \\
\zeta=0.5+\sqrt{\frac{k d_{b w}}{l_{s}}} \leq 1.2 \\
k=\frac{\sqrt{\pi}}{2} \sqrt{\frac{f_{y}}{f_{t}}}\end{array}$ \\
\hline
\end{tabular}




\begin{tabular}{|c|c|c|}
\hline 8 & Chen [34] & $v=\frac{0.6\left(2-0.4 \frac{a}{h}\right)(\rho+2)(1-0.25 h)}{\sqrt{f_{c}^{\prime}}} \leq 1$ \\
\hline 9 & Warwick and Foster [26] & $v=1.25-\frac{f_{c}^{\prime}}{500}-0.72\left(\frac{a}{d}\right)+0.18\left(\frac{a}{d}\right)^{2} \leq 1.0$ \\
\hline
\end{tabular}

$\varepsilon_{1}$ is the principal tensile strain of concrete, $a / d$ is the shear span-to-depth ratio, $\xi$ is the size effect factor, $\zeta$ is the web effect factor, $d_{b w}$ is the rebar diameter of web reinforcement, $l_{s}$ is the distance between the web reinforcement, $k$ is the factor for a particular reinforcement grade and concrete strength, $f_{y}$ and $f_{t}$ yield strength of steel bar and concrete tensile strength, respectively. For beams without web reinforcement, the value of $l_{s}$ is taken as the entire length of the strut and $d_{b}$ will be the minimum diameter of the main longitudinal steel bars and the value of $k$ should be divided by $2, \frac{a}{h}$ is the shear span to overall depth ratio, $h$ is the overall section depth in meter, $\rho$ is the longitudinal reinforcement ratio.

Table 7: Mean, SD and CV values of the experimental-to-calculated load capacities using the collected effectiveness factors

\begin{tabular}{|c|c|c|c|c|}
\hline & \multirow{2}{*}{ Reference } & \multicolumn{3}{|c|}{ Experimental/calculated } \\
\cline { 3 - 5 } & Mean & SD \% & CV \% \\
\hline 1 & Rogowsky and MacGregor [28] & 0.60 & 9.0 & 15.1 \\
\hline 2 & Marti [29] & 0.85 & 12.8 & 15.1 \\
\hline 3 & Nielsen [16] & 0.96 & 14.0 & 14.6 \\
\hline 4 & Bergmeister et al.[30] & 0.76 & 11.4 & 15.0 \\
\hline 5 & Collins and Mitchell [31] & 2.60 & 85.3 & 32.8 \\
\hline 6 & Foster and Gilbert [32] & 1.44 & 62.1 & 43.1 \\
\hline 7 & Tan and Cheng [33] & 0.58 & 9.2 & 15.8 \\
\hline 8 & Chen [34] & 1.50 & 23.8 & 15.9 \\
\hline 9 & Warwick and Foster [26] & 1.02 & 24.7 & 24.1 \\
\hline
\end{tabular}

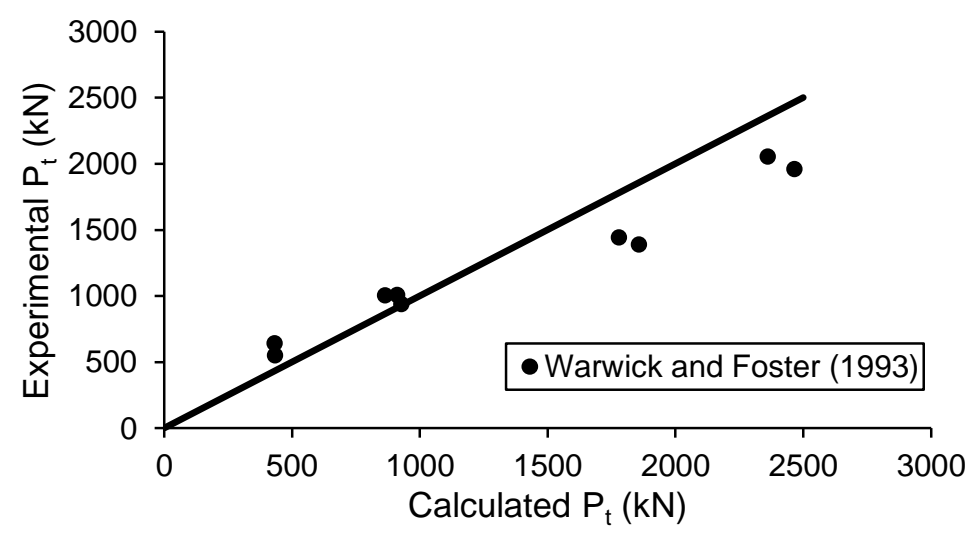


Fig. 8: Comparisons between the experimental and predicted results using Warwick and Foster's effectiveness factor

\subsection{Proposed effectiveness factor for STM}

As mentioned earlier, the effectiveness factor of the European STM gave more reasonable predictions than those suggested by other codes and research investigations, however, the effects of web reinforcement and section size were not taken into consideration. Therefore, based on the current experimental results a regression analysis was performed to suggest a new effectiveness factor for the STM able to safely estimate the load capacity of two-span concrete deep beams reinforced with GFRP bars. The new effectiveness factor was based on that recommended by the Euro code with consideration of the section size and web reinforcement effects. The effects of concrete compressive strength $\left(v_{f_{c}^{\prime}}\right)$, section size $\left(v_{\text {size }}\right)$ and the orthogonal web reinforcement $\left(v_{w e b}\right)$ were considered in the proposed effectiveness factor through Eqs 13, 14 and 15, respectively, as follows:

$$
\begin{aligned}
& v_{f_{c}^{\prime}}=0.7\left(1-\frac{f_{c}^{\prime}}{250}\right) \\
& v_{\text {size }}=0.96\left(\frac{300}{h}\right)^{0.28} \leq 1.0 \\
& v_{w e b}=1+0.1 \frac{a}{h}\left(\frac{\rho_{v}+\rho_{h}}{0.8}\right)
\end{aligned}
$$

Therefore, the suggested effectiveness factor can be written as:

$$
v=v_{f_{c}^{\prime}} v_{\text {size }} v_{w e b}=0.672\left(1-\frac{f_{c}^{\prime}}{250}\right)\left(\frac{300}{h}\right)^{0.28}\left[1+0.1 \frac{a}{h}\left(\frac{\rho_{v}+\rho_{h}}{0.8}\right)\right]
$$

where, $\rho_{v}=\frac{100 A_{v}}{b S}$ and $\rho_{h}=\frac{100 A_{h}}{b S}$ are the vertical and horizontal web reinforcement ratios, respectively, $S$ is the spacing centre to centre between the web reinforcement, $A_{v}$ and $A_{h}$ are the areas of the vertical and horizontal web reinforcement, respectively.

The same procedure of solution presented earlier to calculate the total load capacities using the effectiveness factors suggested by the code provisions, namely Eqs 1 to 12, was used with the proposed effectiveness factor to predict the shear and total load capacities of the tested specimens. Table 5 and Fig. 9 show the comparison between the predicted total load capacities using the proposed effectiveness factor and those obtained from the experimental study. The internal shear strength, $V_{I}$, calculated from Eq. 4 of all the test specimens governed the predicted total load capacity calculated from Eq. 12, agreeing with the finding 
of the experimental results. Reasonable predictions for the test specimens were achieved using the suggested effectiveness factor of the current study than those suggested by the code provisions and the previous investigations. The mean and coefficient of variation values for the ratio between the experimental and the calculated results were 1.02 and $5.9 \%$, respectively, as shown in Table 5. The proposed effectiveness factor can estimate the influences of section depth and orthogonal web reinforcement as shown in Fig. 10 that shows the relationship between the normalised total load, $\frac{P_{t}}{b h f_{c}^{\prime}}$, and the section height.

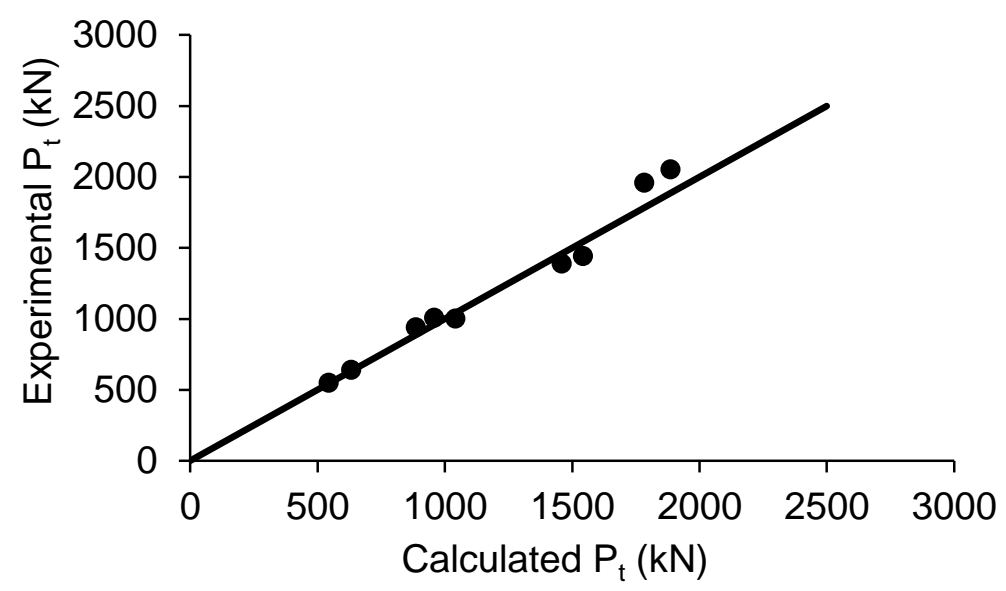

Fig. 9: Comparisons between the experimental results and those predicted by the STM using the proposed effectiveness factor of the current study

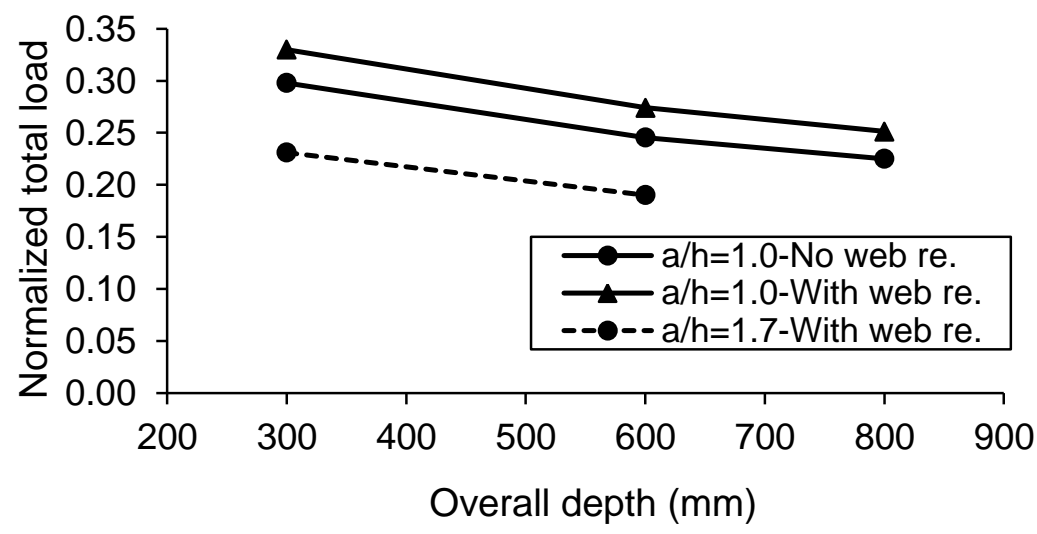

Fig. 10: Web reinforcement and size effects according to the proposed effectiveness factor of the current study

\section{Upper bound analysis}

For complicated cases, such as difficult loading arrangement and beams with openings it is easier to use the upper-bound solutions than the lower-bound analysis [16, 18]. Kinematics and energy principle need to be satisfied to apply the upper-bound analysis [17]. The load carrying capacities of the current tested specimens reinforced with GFRP bars were calculated using the upper bound technique. This method was developed earlier by Ashour and Morley [35] for deep beams reinforced with steel rebars and was based on the failure 
observations of continuous concrete deep beams reinforced with steel bars that were carried out by Ashour [36] and Rogowsky et al. [37]. That failure was represented by a major diagonal crack connecting the intermediate support with the loading plate, separating the beam into two parts: part I rotated about the exterior support, while part II rested over the other two supports as shown in Fig. 11(a). The observed discontinuity failure zone between the two specimen's parts was identified as a yield line [16, 27]. Same failure modes were confirmed by the current experimental investigation on continuous deep beams reinforced with GFRP bars. The steel reinforcement was modelled as a rigid perfectly plastic material in tension and compression with a capacity equal to the yield strength of steel, $f_{y}$. Concrete was assumed to be a rigid perfectly plastic material obeying the modified Coulomb failure criteria with an effective compressive strength of $f_{c e}=v f_{c}^{\prime}$ and zero tensile strength, where $f_{c e}$ is the effective compressive strength of concrete and $v$ is the effectiveness factor of concrete.

An energy principle was applied by equating the external work, $W_{E}$, with the internal energy, $W_{I}$, dissipated along the yield line from concrete, web reinforcement and longitudinal reinforcement. By adding internal energy of concrete to that of reinforcement and equating them to the external energy, the total load capacity, $P_{t}$, can be written in the following form

$$
P_{t}=\frac{1}{a}\left[v f_{c}^{\prime} r_{c}(1-\sin \alpha) \frac{b h}{\sin \beta}+2 \sum_{i=1}^{n}\left(A_{s}\right)_{i}\left(f_{y}\right)_{i}\left(r_{s}\right)_{i} \cos \left(\alpha_{s}\right)_{i}\right]
$$

where $r_{c}$ is the distance between the instantaneous centre and the midpoint of the yield line, $r_{s}$ is the distance between the reinforcing bar crossing the yield line and the instantaneous centre, $\alpha$ is the angle between the yield line and the relative displacement of concrete, $\delta_{c}, \beta$ is the angle between the longitudinal axis and the yield line as shown in Fig. 11(a), $n$ is the number of reinforcing bars crossing the yield line; $\left(A_{s}\right)_{i}$, and $\left(f_{y}\right)_{i}$ is the area and yield strength of the reinforcing bar $i$ crossing the yield line, respectively, $\left(r_{s}\right)_{i}$ is the distance between the reinforcing bar $i$ and the instantaneous centre and $\left(\alpha_{s}\right)_{i}$ is the angle between the relative displacement $\delta_{s}$ about IC and the reinforcing bar $i$ crossing the yield line as shown in Fig. 11(b).

The dissipated energy is mainly influenced by the position of the instantaneous centre IC $\left(X_{i c}, Y_{i c}\right)$ about which the rigid block I of Fig. 11(a) is supposed to rotate; and the properties of the concrete and reinforcement, where $Y_{i c}$ and $X_{i c}$ are the vertical and the horizontal coordinates of the IC.

As shown in Eq. 17 the total failure load is a function of the instantaneous centre location $\left(X_{i c}, Y_{i c}\right)$. As the vertical movement of the rotated part is prohibited by the end support and the horizontal coordinate $\left(X_{i c}\right)$ of the instantaneous centre coincides with that of the global 
coordinates, the total failure load will be a function of vertical coordinate only $\left(Y_{i c}\right)$. By varying the vertical coordinate $\left(Y_{i c}\right)$ of the instantaneous centre along the vertical axis of the global coordinate the minimum value of strength that causes failure is obtained.

The presented upper bound analysis is used in the current study to predict the total failure load of the specimens reinforced with GFRP bars using two effectiveness factors developed by Ashour and his associates for upper bound technique as shown in Table 8. The earlier one was developed by Ashour and Morley [35] based on the previous experimental investigations conducted on continuous concrete deep beams reinforced with steel rebars $[\underline{36}, \underline{37]}$. The suggested factor considered the effects of longitudinal and web reinforcements in addition to concrete compressive strength, while size effect was not taken into consideration. The second effectiveness factor was recommended by Yang et al. [38] based on that suggested by Vecchio and Collins [39] to consider the influences of concrete compressive strength and principal tensile and compressive strains. To reflect the size effect, $\zeta$, Yang et al. adopted the same formula proposed by Bazant and Kim [40] which is a function of section depth and maximum aggregate size as shown in Table 8.

Table 9 shows the relationship between the experimental results of the current study and those calculated by the upper-bound analysis using Yang et al.'s effectiveness factor. As the tensile strength of GFRP bars is much higher than that of steel reinforcement, the term $\lambda$ in Ashour and Morley's effectiveness was higher. Therefore, some specimens reinforced with GFRP bars showed $v<0$, accordingly, only the results obtained from Yang et al.'s effectiveness factor are presented in Table 9. The results showed that Yang et al.'s effectiveness factor overestimated the calculated load capacities with mean and a coefficient of variation values for the experimental-to-calculated results of 0.67 and $38.3 \%$, respectively. The main reason of this unsafe estimation is related to the use of a total tensile strength of GFRP reinforcement, namely $920 \mathrm{MPa}$ and $760 \mathrm{MPa}$ for $16 \mathrm{~mm}$ and $20 \mathrm{~mm}$ GFRP bars, respectively. Experimentally, it was found that the tensile stresses in the GFRP bars of all specimens at failure were much lower than their tensile strength. Therefore, the influence of GFRP reinforcement should be restricted by a reasonable way to coincide with its real contribution. Accordingly, the current upper-bound analysis needs to be modified to be able to consider the effect of GFRP reinforcement. 


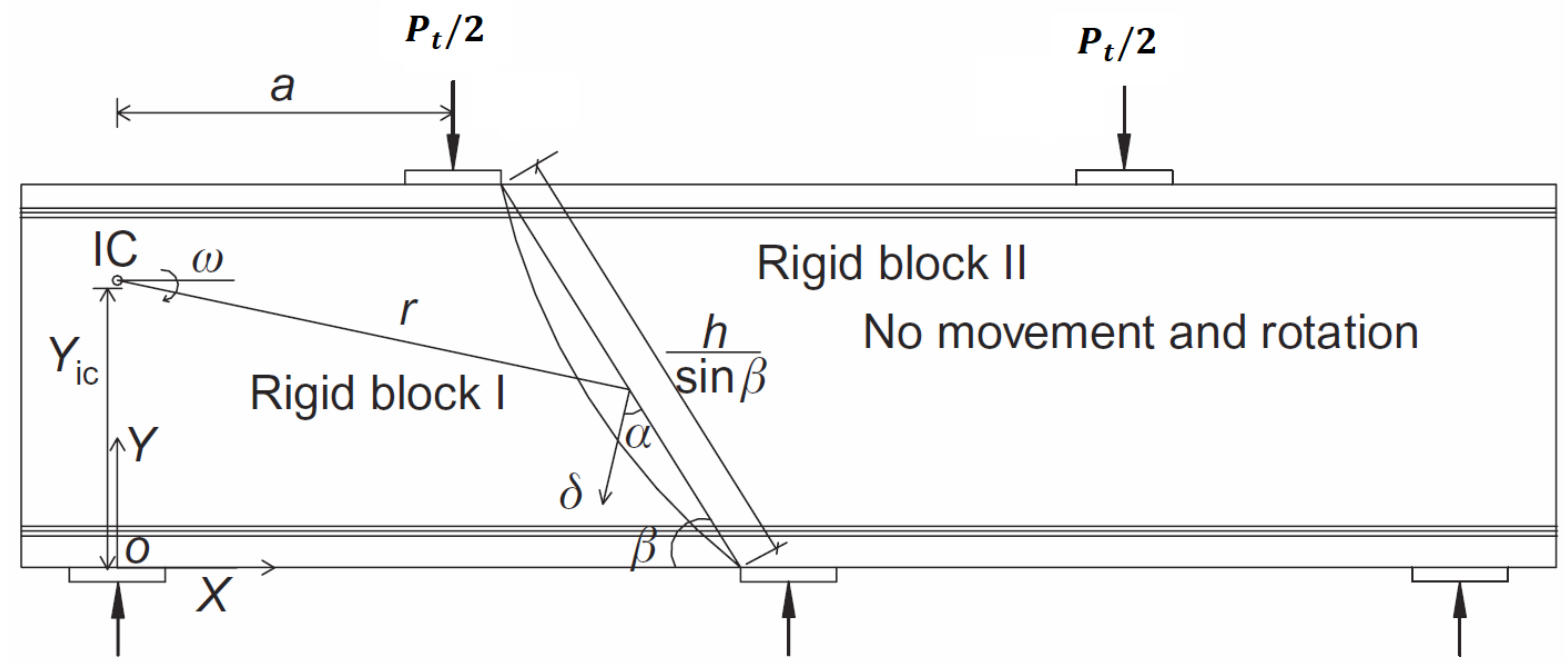

(a)

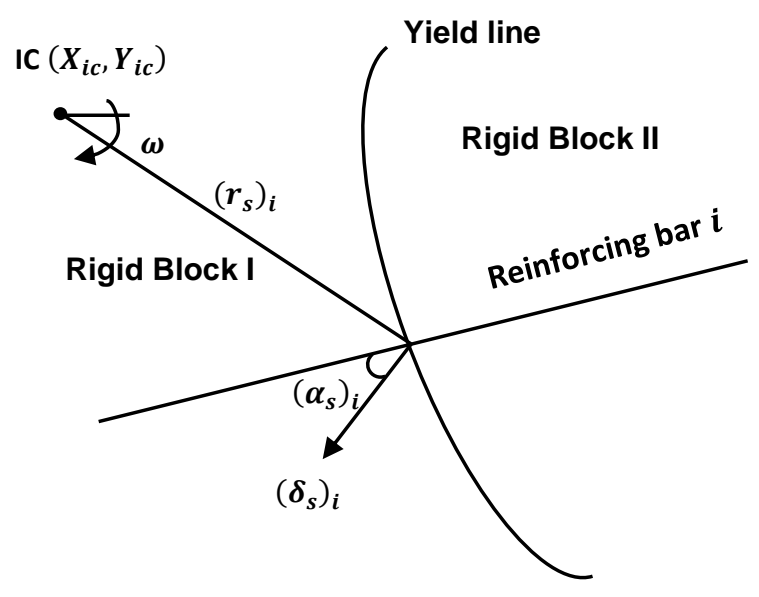

(b)

Fig. 11: (a) Failure mechanism of two spans continuous deep beams, (b) reinforcing bar crossing yield line [38]

Table 8: Effectiveness factors suggested previously for the upper bound analysis

\begin{tabular}{|c|c|c|c|}
\hline & Reference & Effectiveness factor equation & Notes \\
\hline \multirow{4}{*}{1} & $\begin{array}{l}\text { Ashour and } \\
\text { Morley [35] }\end{array}$ & $v=0.77-\frac{f_{c}^{\prime}}{110}-\frac{\lambda}{0.85}$ & $\lambda=\phi_{b}+\sum_{i=1}^{N_{w}} \phi_{w} \frac{d_{i}}{h}$ \\
& & & $\emptyset_{b}=\frac{A_{b} f_{y}}{b h f_{c}^{\prime}}$ \\
\hline
\end{tabular}




\begin{tabular}{|c|c|c|c|}
\hline 2 & Yang et al. [38] & $v=\frac{\zeta}{1+k_{c} k_{f}}$ & $\begin{array}{c}k_{c}=0.35\left(-\frac{\varepsilon_{1}}{\varepsilon_{2}}-0.28\right)^{0.8} \geq 1.0 \\
-\frac{\varepsilon_{1}}{\varepsilon_{2}}=\frac{1+\sin \alpha}{1-\sin \alpha} \\
k_{f}=0.1825 \sqrt{f_{c}^{\prime}} \geq 1.0 \\
\zeta=\frac{1}{\sqrt{1+\frac{d}{25 d_{a}}}}\end{array}$ \\
\hline \multicolumn{4}{|c|}{$\begin{array}{l}\text { Where } \emptyset_{b} \text { is the degree of bottom longitudinal reinforcement, } N_{w} \text { number of horizontal and } \\
\text { vertical web reinforcement bars crossing the yield line, } \phi_{w} \text { is the degree of web } \\
\text { reinforcement bar at a distance } d_{i} \text { from the instantaneous centre, } A_{b} \text { is the area of bottom } \\
\text { longitudinal reinforcement bars, } \varepsilon_{1} \text { and } \varepsilon_{2} \text { are the principal tensile and compressive strains } \\
\text { of concrete in the yield line, respectively, } d_{a} \text { is the maximum size of coarse aggregate. }\end{array}$} \\
\hline
\end{tabular}

\subsection{Proposed effectiveness factors for the upper-bound analysis}

To capture the behaviour observed in the experiments, two effectiveness factors are proposed: one for concrete and the other for GFRP bars. Compressive strength and size effect were considered in the proposed concrete effectiveness factor using the same terms that reflected their effects in that suggested earlier for the STM as follows:

$$
v=0.576\left(1-\frac{f_{c}^{\prime}}{250}\right)\left(\frac{300}{h}\right)^{0.28}
$$

The effect of web reinforcement has not been included in Eq. 18, because the contribution of web reinforcement has already been considered by the upper-bound model, as shown in Eq. 17.

The observed failure nature and the experimental results of the strain readings in the longitudinal and web reinforcement bars showed that the GFRP bars did not rupture and the tensile stresses in reinforcing bars were much lower than their tensile strengths. Additionally, the bond strength of GFRP bars is less than that of steel rebars, and hence, the contribution of GFRP bars to improve the load capacity is limited compared with that of steel rebars. The low bond strength of GFRP bars results in inappropriate transferring of stresses between concrete and reinforcement. Accordingly, the deboning failure of FRP bars in concrete deep is more likely to occur than tensile rupture, therefore, the energy dissipated from GFRP bars was calculated based on the bond strength value of FRP reinforcement. Additionally, the 
brittle manner of FRP reinforcement needs to be taken into account when the plasticity theory is applied. Thus, to consider all of the mentioned reasons, a new effectiveness factor is recommended to reasonably reflect the energy dissipated by GFRP bars, as follows:

$$
v_{F R P}=8 \frac{u}{F_{u}}
$$

where $v_{F R P}$ is the proposed effectiveness factor for GFRP reinforcement, $u$ is the bond strength, $F_{u}$ is the tensile strength of GFRP reinforcement. The bond strength values $(u)$ were obtained experimentally from the pullout tests suggested by the $\mathrm{ACl} 440.3 \mathrm{R}$ (2012) as shown in Table 2. Pullout specimens were cast from the same concrete batches used for the deep beam specimens. The bond specimen consisted of a single bar embedded vertically in the $200 \mathrm{~mm}$ concrete cubes along the central axis of the specimen with an embedment length of 5 times the bar diameter as recommended by ACI 440.3R (2012). An average value of three identical specimens for each bar diameter is shown in Table 2. Based on the aforementioned, Eq. 17 can be modified to be as follows:

$$
P_{t}=\frac{1}{a}\left[v f_{c}^{\prime} r_{c}(1-\sin \alpha) \frac{b h}{\sin \beta}+2 \sum_{i=1}^{n} v_{F R P}\left(A_{F}\right)_{i}\left(F_{u}\right)_{i}\left(r_{s}\right)_{i} \cos \left(\alpha_{s}\right)_{i}\right]
$$

where $\left(A_{F}\right)_{i}$ and $\left(F_{u}\right)_{i}$ are the area and tensile strength of GFRP reinforcement crossing the yield line, respectively. $v$ and $v_{F R P}$ in Eq. 21 are calculated from Eqs. 18 and 19, respectively.

\subsection{Load capacity predictions using the modified upper-bound analysis}

The experimental results of the specimens reinforced with GFRP bars were compared with the predicted ones using the modified upper-bound analysis shown in Eq. 20. Fig. 12 and Table 9 show the calculated total load capacities against those obtained from the current experimental study. A good agreement between the predicted results and the experimental ones was obtained with a mean and a coefficient of variation for the ratio between the experimental and calculated load capacities of 1.03 and $8.6 \%$, respectively. Accordingly, it can be concluded that, for the range of parameters considered in the specimens tested, the suggested effectiveness factors for concrete and GFRP bars were able to consider the influences of section size, web reinforcement and GFRP bars on the behaviour of two-span continuous deep beams under concentrated load at mid-span. However, the availability of more experimental results for continuous concrete deep beams reinforced with FRP bars in the future will help to validate or even recalibration the proposed effectiveness factors. 


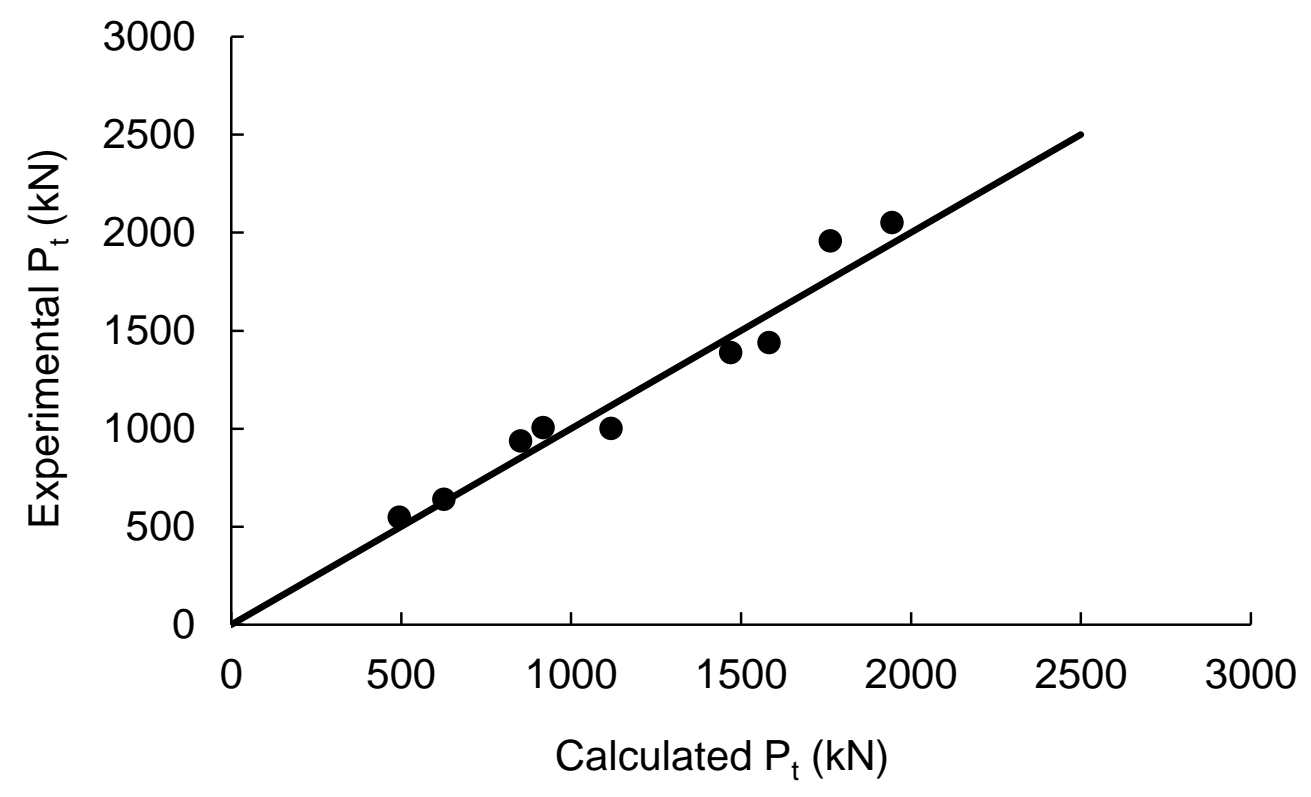

Fig. 12: Comparisons between experimental results and predictions of upper-bound analysis using the suggested effectiveness factors of the current study

Table 9: Comparisons between the test results and predictions of the upper-bound analysis using the previous and the proposed effectiveness factors

\begin{tabular}{|c|c|c|c|c|c|}
\hline \multirow{2}{*}{ Specimens } & \multirow{2}{*}{$P_{t \text { Exp }}$} & \multicolumn{2}{|c|}{ Yang et al. [38] } & \multicolumn{2}{c|}{ Proposed (current study) } \\
\cline { 3 - 6 } & & $\begin{array}{c}P_{t \text { Cal }} \\
(\mathrm{kN})\end{array}$ & $P_{t \text { Exp }} / P_{t \text { Cal }}$ & $\begin{array}{c}P_{t \text { Cal }} \\
(\mathrm{kN})\end{array}$ & $P_{t \text { Exp }} / P_{t \text { Cal }}$ \\
\hline G1-300-N & 937.3 & 989.2 & 0.95 & 851.5 & 1.10 \\
\hline G1-300-W & 1005.8 & 1558.9 & 0.65 & 918.2 & 1.10 \\
\hline G1-600-N & 1388.0 & 1851.0 & 0.75 & 1469.4 & 0.94 \\
\hline G1-600-W & 1439.4 & 2981.0 & 0.48 & 1582.8 & 0.91 \\
\hline G1-800-N & 1957.1 & 2402.0 & 0.81 & 1762.7 & 1.11 \\
\hline G1-800-W & 2050.3 & 4104.9 & 0.50 & 1944.5 & 1.05 \\
\hline G1.7-300-N & 547.8 & 495.4 & 1.11 & 494.3 & 1.11 \\
\hline G1.7-300-W & 639.7 & 1485.3 & 0.43 & 625.8 & 1.02 \\
\hline G1.7-600-W & 1000.5 & 2928.1 & 0.34 & 1117.3 & 0.90 \\
\hline \multirow{2}{*}{} & & Mean & 0.67 & Mean & 1.03 \\
\cline { 3 - 6 } & & SD \% & 25.6 & SD \% & 8.83 \\
\cline { 3 - 6 } & CV\% & 38.3 & CV\% & 8.60 \\
\cline { 3 - 6 } & & & & &
\end{tabular}




\section{Conclusions}

In this paper, the STM was simplified to estimate the total failure loads of the specimens tested. The effectiveness factors proposed by the American, European and Canadian codes as well as those suggested by previous researchers were evaluated. As these factors were unable to reflect the influences of section size and/or web reinforcement, a new effectiveness factor was recommended to be used with the STM. Additionally, by using two effectiveness factors, one for concrete and the other for GFRP bars, the upper-bound analysis was developed. Interestingly, the same terms that were used to reflect the influences of compressive strength and size effect in the STM suggested effectiveness factor were also adopted for that used in the upper bound analysis. Another effectiveness factor was also proposed to capture the low bond between GFRP bars and concrete as these bars do not rupture at the failure of deep beams tested. The main conclusions of the carried out investigations can be summarized below:

- The comparisons between the test results and those calculated using the strut-andtie methods suggested by the American (ACI 318-2014), European (EC2-2004) and Canadian (S806-2012) codes showed that the American code gave unsafe predictions, while the predictions obtained from the Canadian code underestimated the load capacity of the beams tested. Compared with the American and Canadian codes, the European code provided the closest predictions to the test results but non-consideration of the influences of the section depth and web reinforcement on the shear strength that the current experimental study confirmed their impacts.

- For the lower bound analysis, the effectiveness factors collected from the previous investigations were unable to reflect adequately the impacts of the section depth and/or web reinforcement on the load capacities of the specimens reinforced with GFRP bars.

- The effectiveness factor suggested in the current investigation that considered the influences of section depth and web reinforcement gave better predictions with the STM than those proposed by the codes and previous investigations. However, more related experiments need to be introduced in the future to validate and recalibrate the proposed effectiveness factor.

- The upper bound analysis suggested earlier for the specimens reinforced with steel rebars overestimated the predicted loads of the specimens reinforced with GFRP bars. 
- The proposed effectiveness factors used to modify the upper bound analysis achieved a good agreement between the measured load capacities and the calculated once.

\section{Acknowledgments}

The authors would like to express their special thanks and gratitude to the Higher Committee of Education Development in Iraq (HCED) for their financial support.

APPENDIX (A)

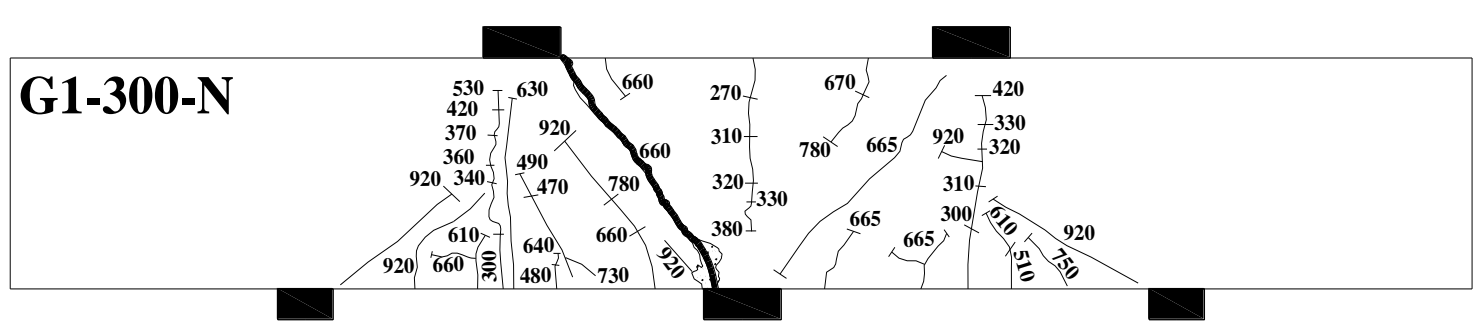

(a) G1-300-N 


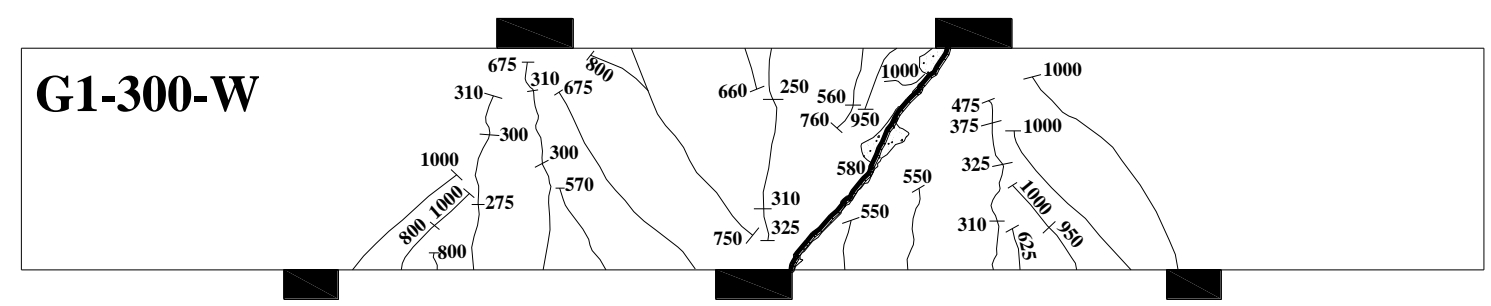

(b) G1-300-W

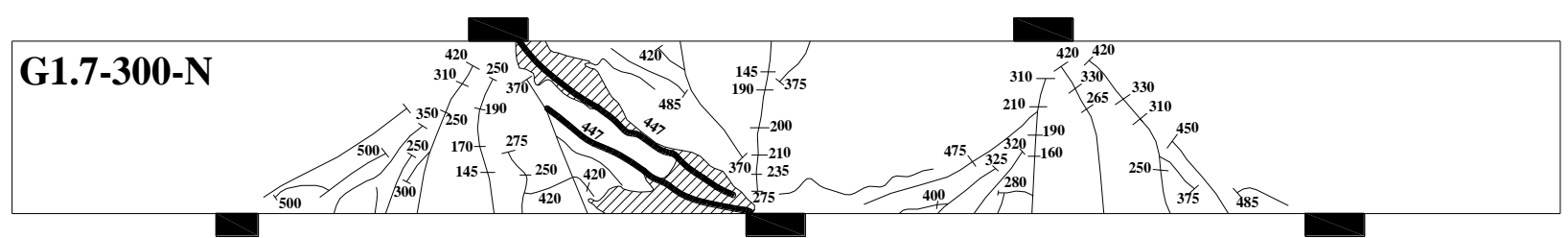

(c) G1.7-300-N

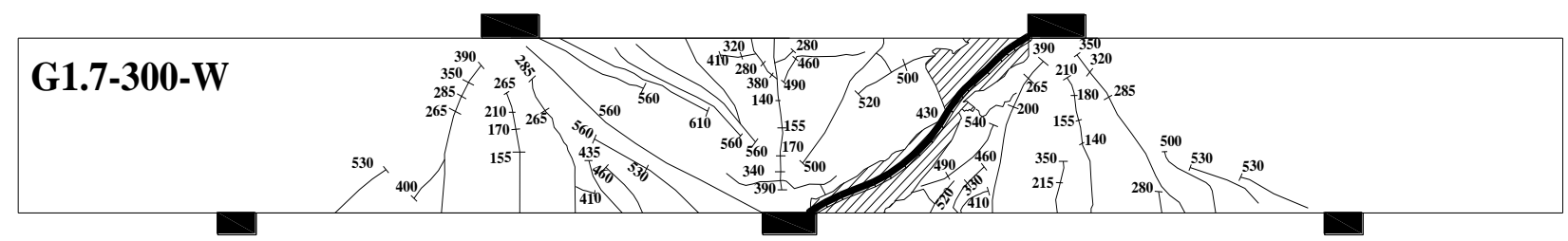

(d) G1.7-300-W

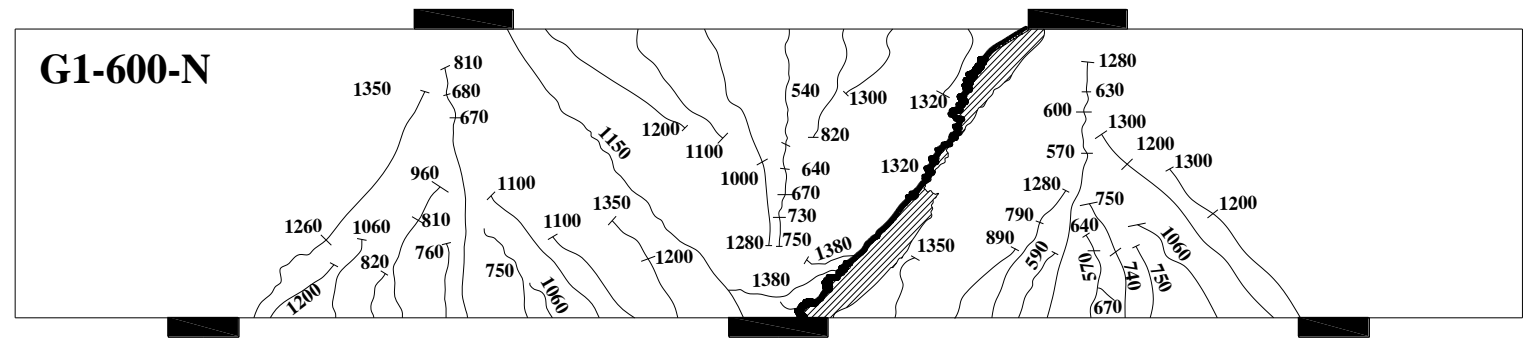

(e) G1-600-N

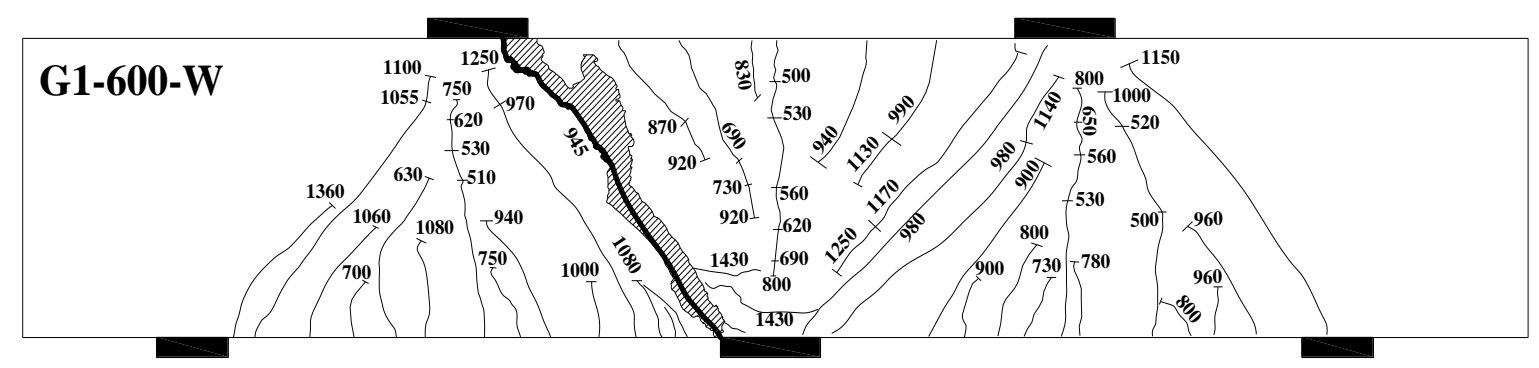

(f) G1-600-W 


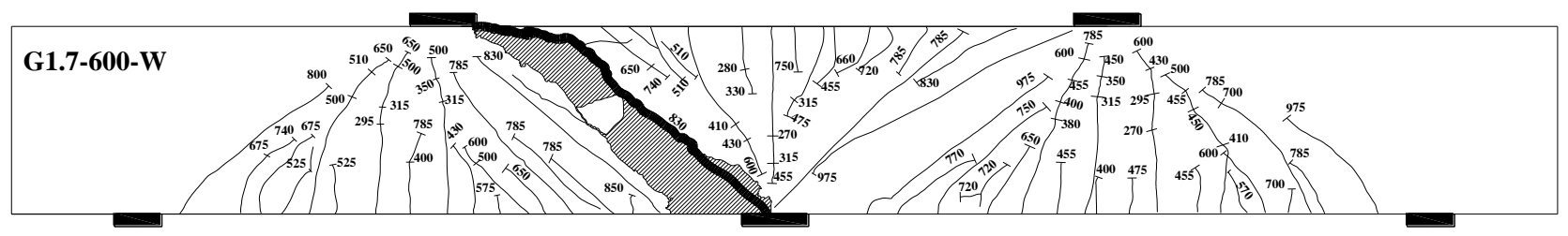

(g) G1.7-600-W

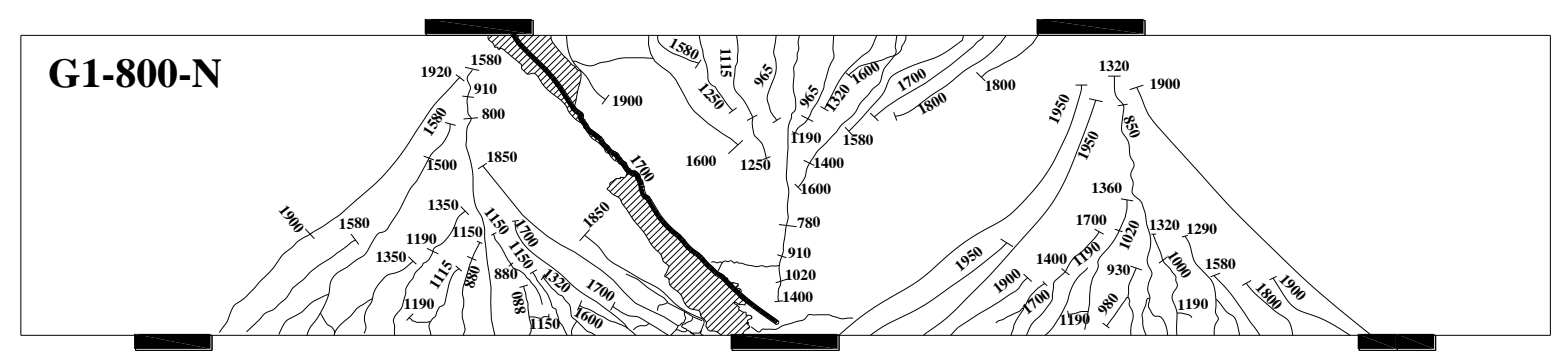

(h) G1-800-N

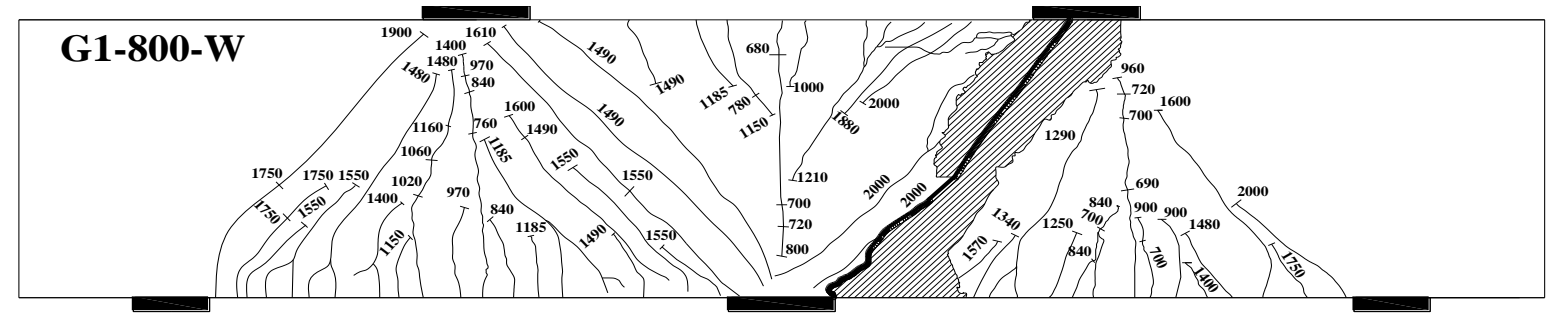

(i) G1-800-W

Fig. A.1: Cracking propagations and failure modes of the test beams

The diagonal cracks which were the cause of the beams failure are marked in bold in Fig. A.1, while the hatchings refer to the crushing of concrete.

\section{References}

[1] $\mathrm{ACl}$ Committee $318 \mathrm{M}$, Building Code Requirements for Structural Concrete and Commentary. 2014, ACl, Farmington Hills, Michigan. p. 619.

[2] Eurocode 2: Design of concrete structures: Part 1-1: General rules and rules for buildings. 2004, European Committee for Standardization, CEN.

[3] Canadian Standards Association A23.3, Design of concrete structures for buildings with explanatory notes. 2004, Canadian Standards Association, Rexdale, ON, Canada.

[4] Canadian Standards Association S806, Design and construction of building components with fiber-reinforced polymers. 2012, Canadian Standards Association, Mississauga, Ontario, Canada. p. 208. 
[5] Nehdi, M., Z. Omeman, and H. El-Chabib, Optimal efficiency factor in strut-and-tie model for FRP-reinforced concrete short beams with $(1.5<a / d<2.5)$. Materials and structures 2008; 41(10):1713-1727.

[6] Kim, D.-J., J. Lee, and Y.H. Lee, Effectiveness factor of strut-and-tie model for concrete deep beams reinforced with FRP rebars. Composites Part B: Engineering 2014; 56:117-125.

[7] Andermatt, M.F. and A.S. Lubell, Strength modeling of concrete deep beams reinforced with internal fiber-reinforced polymer. ACI Structural Journal 2013; 110(4):595-605.

[8] Farghaly, A.S. and B. Benmokrane, Shear behavior of FRP-reinforced concrete deep beams without web reinforcement. Journal of Composites for Construction 2013; 17(6):04013015.

[9] Mohamed, K., A.S. Farghaly, and B. Benmokrane, Strut Efficiency-Based Design for Concrete Deep Beams Reinforced with Fiber-Reinforced Polymer Bars. ACI Structural Journal 2016; 113(4):791-800.

[10] Abu-Obaida, A., B. El-Ariss, and T. El-Maaddawy, Behavior of Short-Span Concrete Members Internally Reinforced with Glass Fiber-Reinforced Polymer Bars. Journal of Composites for Construction 2018; 22(5):04018038.

[11] Andermatt, M.F. and A.S. Lubell, Behavior of concrete deep beams reinforced with internal fiber-reinforced polymer-experimental study. ACI Structural Journal 2013; 110(4):585-594.

[12] Mohamed, K., A.S. Farghaly, and B. Benmokrane, Effect of Vertical and Horizontal Web Reinforcement on the Strength and Deformation of Concrete Deep Beams Reinforced with GFRP Bars. Journal of Structural Engineering 2017; 143(8):04017079

[13] El-Sayed, A.K., E.F. El-Salakawy, and B. Benmokrane, Shear strength of fibre-reinforced polymer reinforced concrete deep beams without web reinforcement. Canadian Journal of Civil Engineering 2012; 39(5):546-555.

[14] Schlaich, J., K. Schäfer, and M. Jennewein, Toward a consistent design of structural concrete. $\mathrm{PCl}$ journal 1987; 32(3):74-150.

[15] Chen, W.-F., Plasticity in reinforced concrete. 1982, McGraw-Hill, New York.

[16] Nielsen, M.P., Limit analysis and concrete plasticity. 1984: Prentice Hall.

[17] EL-Metwally, S. and Chen, W. F., Structural Concrete: Strut-and-Tie Models for Unified Design. 2017, CRC Press.

[18] Ashour, A., Shear capacity of reinforced concrete deep beams. Journal of Structural Engineering 2000; 126(9):1045-1052.

[19] Guide Test Methods for Fiber-Reinforced Polymer (FRP) Composites for Reinforcing or Strengthening Concrete and Masonry Structures. 2012, ACl, Farmington Hills, Michigan.

[20] Zinkaah, O.H., Ashour, A. and Sheehan, T., Experimental tests of two-span continuous concrete deep beams reinforced with GFRP bars and strut-and-tie method evaluation. Composite structures, Submitted and under revision.

[21] Rogowsky, D. and J. MacGregor, Design of reinforced concrete deep beams. Concrete International 1986; 8(8):49-58.

[22] Yang, K.-H., H.-S. Chung, and A.F. Ashour, Influence of shear reinforcement on reinforced concrete continuous deep beams. ACI Structural Journal 2007; 104(4):420-429.

[23] Yang, K.-H. and A.F. Ashour, Load capacity of reinforced concrete continuous deep beams. Journal of structural engineering 2008; 134(6):919-929.

[24] Yang, K.-H. and A. Ashour, Code modelling of reinforced-concrete deep beams. Magazine of Concrete Research 2008; 60(6):441-454.

[25] Latosh, F.A., Structural behaviour of conventional and FRP reinforced concrete deep beams. 2014, PhD thesis, Concordia University, Montréal, Québec, Canada.

[26] Warwick, W. and S.J. Foster, Investigation into the efficiency factor used in non-flexural reinforced concrete member design. 1993: University of New South Wales.

[27] Ashour, A.F. and K.-H. Yang, Application of plasticity theory to reinforced concrete deep beams. Magazine of Concrete Research 2008; 60(9):657-664. 
[28] Rogowsky, D.M., and MacGregor, J. G., shear strength of deep reinforced concrete continuous beams. 1983, Structural Engineering Rep. No. 110, Dept. of Civil Engineering, Univ. of Alberta, Edmonton, Canada. p. 178.

[29] Marti, P., Basic tools of reinforced concrete beam design. ACl Structural Journal 1985; 82(1):46-56.

[30] Bergmeister, K., J. Breen, and J. Jirsa. Dimensioning of the nodes and development of reinforcement. in IABSE Colloquium Stuttgart, International Association for Bridge and Structural Engineering, Zurich. 1991.

[31] Collins, M.P. and D. Mitchell, Rational Approach to Shear Design--The 1984 Canadian Code Provisions. ACl structural journal 1986; 83(6):925-933.

[32] Foster, S.J. and R.I. Gilbert, The design of nonflexural members with normal and highstrength concretes. ACI Structural Journal 1996; 93(1):3-10.

[33] Tan, K. and G. Cheng, Size effect on shear strength of deep beams: Investigating with strutand-tie model. Journal of Structural Engineering 2006; 132(5):673-685.

[34] Chen, G., Plastic analysis of shear in beams, deep beams and corbels. 1988: Rep. No. R 237, Dept. of Structural Engineering, Technical Univ. of Denmark, Copenhagen.

[35] Ashour, A. and C. Morley, Effectiveness factor of concrete in continuous deep beams. Journal of Structural Engineering 1996; 122(2):169-178.

[36] Ashour, A.F., Behaviour and strength of reinforced concrete continuous deep beams. 1994, Univ. of Cambridge, Cambridge, England.

[37] Rogowsky, D.M., J.G. MacGregor, and S.Y. Ong, Tests of reinforced concrete deep beams. ACl Structural Journal 1986; 83(4):614-623.

[38] Yang, K.-H., H.-S. Chung, and A. Ashour, Influence of section depth on the structural behaviour of reinforced concrete continuous deep beams. Magazine of concrete research 2007; 59(8):575-586.

[39] Vecchio, F.J. and M.P. Collins, Compression response of cracked reinforced concrete. Journal of Structural Engineering 1993; 119(12):3590-3610.

[40] Bazant, Z.P. and J.-K. Kim, Size effect in shear failure of longitudinally reinforced beams. ACl Structural Journal 1984; 81(5):456-468.

\section{Notations/symbols}

$\left(A_{s}\right)_{i} \quad$ Area of the reinforcing bar $i$ crossing the yield line

$\left(f_{y}\right)_{i} \quad$ Yield strength of the reinforcing bar $i$ crossing the yield line

$\left(r_{s}\right)_{i} \quad$ Distance between the reinforcing bar $i$ and the instantaneous centre

$\left(\alpha_{s}\right)_{i} \quad$ Angle between the relative displacement $\delta_{s}$ about IC and the reinforcing bar $i$ crossing the yield line

$\left(W_{E S}\right)_{b} \quad$ Bottom width of the exterior strut

$\left(W_{E S}\right)_{t} \quad$ Top width of the exterior strut

$\left(W_{I S}\right)_{b} \quad$ Bottom width of the interior strut 
$\left(W_{I S}\right)_{t} \quad$ Top width of the interior strut

$\left(X_{i c}, Y_{i c}\right) \quad$ Horizontal and vertical coordinates of the instantaneous centre

$\emptyset_{b}$

$A_{h}$

$A_{b}$

$A_{f}$

$A_{v}$

$E_{f}$

$F_{E}$

$F_{I}$

$F_{u}$

$N_{w}$

$P_{t}$

$V_{E}$

$V_{I}$

$W_{E}$

$W_{E S}$

$W_{I}$

$W_{I S}$

$W_{b n}$

$W_{t n}$

$c_{b}$

$d_{a}$

$d_{b}$

$d_{b w}$

$d_{i}$

$f_{c}^{\prime}$

$f_{c e}$

$f_{t}$

$f_{y}$

$l_{E P}$

$l_{I P}$

$l_{L P}$

$l_{d}$

$l_{e}$

$l_{s}$

$r_{c}$

$r_{S}$

$\delta_{c}$

$\delta_{S}$

$\varepsilon_{1}$

$\varepsilon_{2}$

$\varepsilon_{f}$

$\rho_{h}$

$\rho_{v}$
Degree of bottom longitudinal reinforcement

Area of the horizontal web reinforcement

Area of bottom longitudinal reinforcement bars

Area of GFRP bars

Area of the vertical web reinforcement

Modulus of elasticity of the GFRP bars

Load capacity of the exterior concrete struts

Load capacity of the interior concrete struts

Tensile strengths of GFRP reinforcement

Number of horizontal and vertical web reinforcement bars crossing the yield line

Total failure load

External shear strength

Internal shear strength of one span

External work

Average width of the exterior compression struts

Internal energy

Average width of the interior compression struts

Effective width of the bottom tie

Effective width of the top tie

Lesser of the concrete cover to the centre of the bar or half of the centre-to-centre spacing of the bars being developed

Maximum size of coarse aggregate

Bar diameter

Rebar diameter of web reinforcement

Distance of bar $i$ from the instantaneous centre

Concrete compressive strength

Effective compressive strength of concrete

Concrete tensile strength

Yield strength of steel reinforcement

Width of the exterior support bearing plate

Width of the interior support bearing plate

Width of the loading plate

Development length of the longitudinal reinforcement

Embedment length

Distance between the web reinforcement

Distance between the instantaneous centre and the midpoint of the yield line

Distance between the reinforcing bar crossing the yield line and the instantaneous centre

Relative displacement of concrete

Relative displacement of reinforcement

Principal tensile strain of concrete

Principal compressive strain of concrete in the yield line

Strain in the longitudinal reinforcement

Horizontal web reinforcement ratio

Vertical web reinforcement ratio 


$\begin{array}{ll}v_{F R P} & \text { Effectiveness factor of GFRP reinforcement } \\ \phi_{w} & \text { Degree of web reinforcement bar } \\ h & \text { Overall beam depth } \\ \zeta & \text { Web effect factor } \\ \xi & \text { Size effect factor } \\ L & \text { Centre to centre of the beam span } \\ S & \text { Spacing centre to centre between the web reinforcement } \\ a & \text { Shear span } \\ a / h & \text { Shear span-to-overall depth ratio } \\ a / d & \text { Shear span-to- depth ratio } \\ b & \text { Beam width } \\ c & \text { Concrete cover of the bottom longitudinal reinforcements } \\ c & \text { Concrete cover of the top longitudinal reinforcements } \\ d & \text { Effective depth of the concrete section } \\ k & \text { Factor for a particular reinforcement grade and concrete strength } \\ n & \text { Number of reinforcing bars crossing the yield line } \\ u & \text { Bond strength } \\ \alpha & \text { Angle between the yield line and the relative displacement of concrete } \\ \beta & \text { Angle between the longitudinal axis and the yield line of upper-bound } \\ \eta & \text { analysis } \\ \theta & \text { Ratio of the end reaction to the applied load } \\ \rho & \text { Slope of the concrete strut } \\ v & \text { Longitudinal reinforcement ratio } \\ \omega & \text { Concrete effectiveness factor } \\ & \text { Rotational displacement of rigid block I }\end{array}$

